Research Article

\title{
Complex Dynamics Analysis of Closed-Loop Supply Chain considering CSR and Fairness Concerns
}

\author{
Fei Zhang, ${ }^{1,2}$ Zhimin Hu, ${ }^{1}$ Yunzhong Yang, ${ }^{1,2}$ and Xiaogang $\mathrm{Ma} \mathbb{D}^{1,3}$ \\ ${ }^{1}$ School of Management, Wuhan Textile University, Wuhan 430073, China \\ ${ }^{2}$ Research Center of Performance Management, Wuhan Textile University, Wuhan 430073, China \\ ${ }^{3}$ Research Center of Enterprise Decision Support, \\ Key Research Institute of Humanities and Social Sciences in Universities of Hubei Province, Wuhan 430200, China \\ Correspondence should be addressed to Xiaogang Ma; xgma@wtu.edu.cn
}

Received 28 May 2021; Accepted 19 July 2021; Published 14 August 2021

Academic Editor: Baogui Xin

Copyright (c) 2021 Fei Zhang et al. This is an open access article distributed under the Creative Commons Attribution License, which permits unrestricted use, distribution, and reproduction in any medium, provided the original work is properly cited.

\begin{abstract}
This paper constructs a supply chain model composed of a manufacturer and a recycler. The manufacturer's CSR and the recycler's fairness concerns are introduced to the benchmark model in turn, and the optimal decision-making problems under different models are studied and compared. The findings show that the manufacturer's utility will increase and the recycler's utility will decrease when the manufacturer undertakes CSR within a reasonable range. The optimal utility of manufacturers does not change, and the utility of the recycler is affected by the proportion of CSR undertaken by the manufacturer when the recycler considers fairness concerns. Based on the CSR and fairness model, this paper constructs a dynamic decision system of production quantity and eco-innovation effort. We analyze the influence of adjustment speed on the dynamic decision system and obtain the conditions required to maintain system stability. The research conclusion indicates that with the increase of adjusting parameters, the system gradually appears chaotic state from a stable state and the chaotic state of the system has a negative impact on the utility of manufacturer and recycler. In order to avoid chaos in the system, this paper uses the delayed feedback method to control the system.
\end{abstract}

\section{Introduction}

Due to the rapid economic growth and urbanization, major environmental burdens such as energy (resource) depletion, water pollution, and climate change have forced many countries to require manufacturers to assume extended producer responsibility (EPR) regulations. Extended producer responsibility (EPR) was first proposed by Thomas Lindhqvist, an economist at Lund University. It was in a report submitted to the Swedish Ministry of Environment in 1988. The report believed that producers' responsibility should extend to the whole product life cycle, including product design, recycling, and final disposal [1]. The EPR regulations have attracted wide attention from many scholars since they were proposed. Lifset [2] believed that EPR is an incentive-based environmental policy. Porter and Kramer [3] argued that EPR can be a powerful source of innovation and competitive advantage, not just cost, constraints, or philanthropic behavior. In order to facilitate product recycling, manufacturers need to carry out ecological innovation designs for products. Subramanian et al. [4] studied the coordination between product design and closed-loop supply chain under the EPR environment from the perspective of product energy consumption and product innovation design strategy. As a management system to solve the environmental problems of waste resources, the fundamental purpose of EPR is to reduce the harm of products to the environment through the manufacturers to fulfill the EPR regulations. Currently, more than 30 countries and regions, including China, Germany, Sweden, and Japan, have implemented the EPR system. In 2009, China promulgated, "The Regulations on the Management of Recycling and Disposal of Waste Electrical and Electronic Products," and in 2016, it further promulgated, "The Plan for 
the Implementation of the Extended Producer Responsibility System." At present, the Chinese government is exploring the construction of the EPR system for four major industries: electrical appliances and electronics, automobiles, lead batteries, and packaging materials. These EPR regulations require manufacturers to perform dual tasks. One of the tasks is to promote ecological innovation in the production phase, focusing on reducing resource consumption and preventing waste. Another task is to increase the recovery ratio during the recovery phase. The dual task leads to an environmentally friendly manufacturing and recycling system [5].

With the introduction of EPR regulations, the level of corporate social responsibility (CSR) has become an important indicator to evaluate the reputation of enterprises. According to reports, under the government subsidy mechanism, $61 \%$ of consumers' purchasing decisions are influenced by corporate CSR behavior [6]. While taking on CSR in the short term means increasing costs, a CSR strategy is potentially profitable. Servaes and Tamayo [7] showed in their research that those enterprises actively undertaking social responsibility will gain greater corporate profit. Pino et al. [8] showed that whether a company undertakes social responsibility has a significant impact on consumers' choice of its products. In reality, the Sanlu Group collapsed due to the unqualified milk powder incident. Abbott Group, The Coca-Cola Company, and many others have suffered serious physical and psychological damage to consumers due to the production of illegal products. They have been denounced by consumers and severely sanctioned by the government. The above incidents occurred because of the manufacturers' failure to perform CSR. Therefore, under the guidance of government policies, more and more large enterprises begin to develop social responsibility standards actively for their supply chain (SC) system. For example, PepsiCo has launched its " 2025 " sustainability agenda, which aims to build a healthier relationship between people and food and achieve sustainable development. Leading international brands such as Walmart, Huawei, and IKEA have incorporated CSR into their strategic management and extended it to the entire supply chain. More and more researches are also introducing CSR into the closed-loop supply chain. Panda et al. [9] introduced social responsibility into the closed-loop supply chain and coordinated the closed-loop supply chain with CSR behavior by designing a profitsharing contract. Hosseini-Motlagh et al. [10] discussed the joint decision of product sustainable design level, CSR investment, and product pricing in a dual-channel closed-loop supply chain with third-party recycling. Liu and Xiao [11] compared the recovery ratio and social welfare of manufacturer recycling and retailer recycling in a closed-loop supply chain considering CSR. The fairness concerns of supply chain members were not considered in these studies.

Compared with the traditional supply chain, the decision-making situation of the closed-loop supply chain is more complex; the decision-making subject is often more difficult to make decisions in accordance with the completely rational thinking mode; and the unreasonable profit distribution is more likely to lead to the occurrence of enterprise fairness concerns. Ferrer and Swaminathan [12] pointed out that there are acts of fairness concern in the supply chain. If the leading enterprises do not adjust their strategies in time, the fairness concern behavior of the subordinate enterprises will have a negative impact on the long-term development of the supply chain. In order to protect their own interests, lower-level enterprises will implement fairness concern behavior in decision-making [13]. Therefore, in order to encourage subordinate enterprises to serve the whole supply chain better and participate actively in recycling, the manufacturer should take the issue of fairness of subordinate enterprises into consideration when making decisions. Thus, we need to take the fairness concerns of the recycler into account in the operation and decision-making of the closed-loop supply chain. Based on the previous analysis, this article introduces the manufacturer's CSR and recycler's fairness concerns into the closedloop supply chain's production and management decisions and compares the profit and utility of the following three models: basic model, CSR model, and CSR and fairness concerns model.

In addition, in reality, there are many order cycles in the production and operation of enterprises, so decision-making is a long-term process. Jin et al. [14] studied the pricing of barrier options under continuous conditions. Since decision-makers do not have complete information about the market and recycler, so manufacturers' eco-innovation efforts and production investments are gradually adjusted according to past business conditions. According to the gradient adjustment mechanism in the dynamic system, the decision-maker can adjust their decision continuously according to the past income, so as to approach the optimal decision. The optimization problem is also involved in Deng et al. [15]. Therefore, this paper uses the nonlinear dynamics theory, introduces the bifurcation diagram, the largest Lyapunov exponent, the decision time-series diagram, etc. to study the stability of the dynamic system, and puts forward the conditions to maintain the stability of the dynamic system. Because chaos will destroy the stability of the system, it not only increases the difficulty for the members of the supply chain to make decisions but also damages the profits of the members of the supply chain, so the chaos control method should be adopted to make the system return from chaos to a stable state.

In short, the specific research issues of this paper are as follows:

(1) How do the manufacturer and the recycler make decisions to optimize their utility?

(2) What is the effect of introducing CSR and fairness concerns on the utility of manufacturer and recycler, respectively?

(3) What are the conditions to maintain the stability of a dynamic decision system? And what is the effect of the delayed feedback control on the chaotic state?

The paper is organized as follows. Section 2 presents the related literature. The basic model is described in Section 3. In this section, comparing utility changes in the basic model, 
CSR model, and CSR and fairness concerns model is also discussed. Section 4 constructs a dynamic decision system based on CSR and fairness concerns model and finds out the stable condition of the dynamic system. And, Section 5 uses the delay feedback control mechanism to control the chaotic phenomenon of the dynamic system. Finally, the conclusions are drawn in Section 6.

\section{Literature Review}

Our study is motivated by three streams of literature: (1) recycling activities in a closed-loop supply chain, (2) CSR and fairness concern behavior, and (3) complex dynamics. On the one hand, we elaborate on the previous research work. On the other hand, we emphasize the gap between this paper and previous studies.

2.1. Recycling Activities in a Closed-Loop Supply Chain. This series of studies mainly solve the problem of the optimal response of enterprises to recycling legislation, covering a wide range of fields, including the selection of recycling agents in the supply chain and the remanufacturing activities of the closed-loop supply chain. For example, Savaskan et al. [16] compared four different structures: the centrally coordinated system, the third-party-led collection, the manufacturer-led collection, and the retailer-led collection. Wang et al. [17] constructed a two-stage remanufacturing production decision-making model and analyzed the impact of the carbon tax on the decision-making of manufacturing and remanufacturing enterprises. Simic and Dimitrijevic [18] discussed the remanufacturing process of the automobile recycling plant, and the optimal decision of storage, recovery, and recycling and landfill disposal is put forward. There are also studies that look at recycling mechanism design. Li et al. [19] discussed the governance mechanism in the actual operation of the formal recycling system from the perspectives of the government and enterprises. Zhou et al. [20] analyzed the impact of government subsidies on environmental performance and social welfare. Wang and Chen [21] proposed policies and regulations for the development of China's scrap car recycling industry. Dong et al. [22] analyzed the impact of cleaner production policies on electroplating enterprises. In fact, when establishing an environmentally friendly manufacturing-recycling system, more attention should be paid to the product design in the production stage [5]. Product design for recyclability mostly focuses on design methods suitable for scrap applicability, such as modular design, recycling design, environmental design, reuse design, and so on [23]. For the design of recycled products, this paper solves the environmental and scrap problems through ecological innovation in product design, rather than the traditional end-of-pipe control method. Some studies have noted eco-innovative products. For example, Chang et al. [24] considered that the introduction of product eco-innovation can reduce the unit price of product manufacturing, increase the unit recovery profit of recyclers, and thus increase the recovery ratio and improve environmental problems. Cao et al. [25] integrated ecological design and recycling and discussed the ERP system and the reverse logistics strategy. Chen and Ulya [26] studied the green supply chain management for manufacturers and retailers to carry out ecological design under the government reward and punishment mechanism but lacked integrated consideration of the recycling and processing behavior of the supply chain.

At present, the literature about recycling behavior mainly focuses on the selection of recycling subjects and recycling remanufacturing and less on the ecological innovative design of recycled products. Unlike previous studies, this paper focuses on the impact of manufacturers' ecological innovation behavior on the recycling ratio of recyclers. On this basis, we combine recycling behavior with CSR and fairness concerns and further study the impact of CSR and fairness concerns on the recycling ratio.

2.2. CSR and Fairness Concerns. The studies that consider CSR behavior in a closed-loop supply chain are roughly divided into two categories. One is analyzed from the perspective of CSR input. For example, Gao et al. [27] showed that the recovery rate of waste products and the profits of supply chain members were positively correlated with the social responsibility effect factors. Modak et al. [28] studied pricing decisions and coordination of a closed-loop supply chain considering CSR input under three recycling channel structures from the perspective of social donations. The other kind of literature analyzed CSR from the perspective of enterprises' CSR consciousness, holding that enterprises can achieve the purpose of improving the interests of stakeholders by setting the goal of maximizing social welfare that takes consumer surplus into account. For example, Panda et al. [9] showed that the CSR awareness of manufacturers is beneficial to increase the channel profits of member enterprises and improve the recycling efficiency of waste products. Shu et al. [29] studied the optimal decision of closed-loop supply chain under the background of social responsibility from the perspective of carbon emission constraint and discussed the impact of carbon emission constraint and enterprise CSR awareness on recycling and remanufacturing decisions. Wu et al. [30] studied the supply chain pricing and coordination decision problem considering CSR and realized the perfect coordination of the supply chain through wholesale price and quantity discount contract.

The above research on considering CSR in the supply chain still assumes that member firms are traditional rational "economic man." However, a group of behavioral scientists, such as Nobel Prize winner Kahneman, have revealed that decision-makers are often irrational. They also pay special attention to the benefits and losses of other stakeholder groups [31]. The study of considering members' fairness concern behavior in the supply chain has attracted extensive attention from scholars at home and abroad. Ma et al. [32] studied the optimal pricing decision of a closed-loop supply chain under four different recycling channel structure models considering retailer's fairness concern behavior and market effort. Wang and $\mathrm{Li}$ [33] studied the influence of 
fairness concern behavior of member enterprises on the pricing strategy of the e-commerce closed-loop supply chain under different power structures. Many scholars have also introduced fairness concern behavior into service supply chain [34], fresh product supply chain [35], and other fields and revealed the effects of fairness concern behavior on positive supply chain optimization and operation from different perspectives.

However, few existing studies have considered the effects of both CSR awareness and fairness concern behavior on supply chain optimization and operation. In fact, because one of the enterprises in the supply chain undertakes CSR, which affects the profits of the whole supply chain, it is usually easier to arouse the fairness concern of other enterprises in the supply chain. Therefore, we combine the CSR of manufacturers with the fairness concern behavior of recyclers to study and analyze, in order to expect the profit change results of the supply chain in this case.

2.3. Complex Dynamics. Many researchers integrated the theory of nonlinear dynamics and complex system into the study of economic systems, which greatly enriches the study of the complexity of the long-term game of economic systems. Lou and Ma [36] analyzed the complex effects of sales efforts and carbon emission reduction efforts in the supply chain of household appliances. Johari et al. [37] investigated manufacturers' pricing decision-making adjustment and studies the impact of corporate social responsibility on decision-making. Ma et al. [38] established an oligarchic game model considering carbon emission reduction constraints and conducted a comprehensive study on complex bifurcation, chaos, and other characteristics. Lou et al. [39] studied the supply chain system of a manufacturer, a traditional retailer, and an online retailer. The bullwhip effect in the supply chain is analyzed by complexity theory, and the chaotic system is controlled by the delay feedback method. Li et al. [40] studied a low-carbon dual-channel supply chain, aiming to analyze the influence of different parameter values on price stability and utility of supply chain system using a two-dimensional bifurcation diagram, parametric graph basin, attractor basin, chaotic attractor, sensitivity to the initial value, etc. Ma and Xie [41] analyzed the factors affecting the stability of the mobile phone supply chain, extended the model to the multiretailer supply chain, and discussed the influence of competition on the stability of the supply chain. Ma et al. [42] established two pricing strategies and analyzed their complex behavior using system dynamics. Ma et al. [43] studied the influence of different channel power structures on pricing decisions. The nonlinear dynamics theory is introduced into the construction of a dynamic system to make it more practical. The delay control is used to bring the chaos back to a stable state. More and more dynamic research literatures focus on chaos in the channel supply chain [44-47] and the closed-loop supply chain [48-50].

Through the above literature review, we find that complex dynamics has been applied in many fields of the supply chain. But there are few researches on dynamic analysis of eco-innovative products closed-loop supply chain. Complex dynamics can vividly depict the decisionmaking process of enterprise long-term operation and then provide inspiration for enterprises in reality. Therefore, this paper attempts to construct a dynamic decision-making model to describe further the decision-maker's process from short- to long-term decision-making.

Previous studies have never introduced CSR, fairness concern behavior, and complex dynamics into the closedloop supply chain at the same time. As the low-carbon economy has gradually become the focus of global attention, it is a very interesting topic to study the impact of ecological innovation design, CSR, and fairness concern behavior of renewable products on the stability and complexity of the supply chain system. Therefore, this paper combines the CSR of manufacturers and the fairness concerns of recyclers to observe the impact and change of manufacturers' eco-innovation effort and recyclers' recycling ratio. In addition, chaos theory is used to analyze the stability of the supply chain system, and the conditions for the system to remain stable are explored. Finally, the chaos state in the dynamic system is effectively controlled by applying reasonable adjustment factors.

\section{Model Description and Solution}

This paper considers a supply chain consisting of a manufacturer and a recycler. The manufacturer produces products and sells them in the market, and the recycler collects used products in the market but has limited capacity to dispose of all the used products. A Stackelberg game is played between the manufacturer and the recycler, in which the manufacturer is the leader and the recycler is the follower.

In this paper, we assume that manufacturers' investment in eco-innovation not only can reduce their own production costs but also can increase the returns of the recycler. This fact is also supported by academic research [51]. Based on a survey of manufacturing firms across a variety of industries, the results indicate a significant positive correlation between firms' environmental management practices (including product design) and operational performance (such as cost reduction).

The demand function is given by $q=a-p$, where $p$ is the selling price of the product and $a$ is the market capacity. For simplicity, $a$ is normalized to 1 . When there is no ecoinnovation effort, the manufacturer will incur unit production cost $c$. With the introduction of eco-innovation effort, the cost per unit of production becomes $c_{m}=c-\sigma e$. The cost of eco-innovation effort that the manufacturer has to put in is $e^{2}$ [52].

The recycler determines the recycling ratio based on the manufacturer's production quantity and eco-innovation effort. There is a cost to dispose of each recycled product, that is, the higher the percentage of used product that recycler collect and process, the higher the transportation, labor, and processing costs. The linear recycling cost structure is $c_{r}=\varphi r$, where the parameter $\varphi$ represents the sensitivity of unit recycling cost to recycling ratio. Higher $\varphi$ 
means it is more expensive and more difficult to recycle a unit of recycled products. Parameter $\theta$ is the unit recycling benefit brought by the manufacturer's ecological innovation at the source to the final recycler. Therefore, after the manufacturer invests in the eco-innovation effort, the unit recycling income of the recycler is $\mathrm{Ir}=k+\theta e$. For the sake of clarity, Table 1 summarizes the notations regarding decision variables and parameters in our model.

3.1. Basic Model. When the manufacturer does not undertake corporate social responsibility and the recycler does not consider the fairness concerns, the profit function of the manufacturer and the recycler can be expressed as follows:

$$
\begin{aligned}
& \pi_{m}=(p-c+\sigma e) q-e^{2}=(1-q-c+\sigma e) q-e^{2}, \\
& \pi_{r}=(k+\theta e-\varphi r) r q .
\end{aligned}
$$

According to the inverse solution method, since $\left(\partial^{2} \pi_{r} / \partial r^{2}\right)=-2 \varphi q<0$, according to the first-order condition $\left(\partial \pi_{r} / \partial r\right)=(k+\theta e-2 \varphi r) q=0$, the optimal recycling ratio response function of the collector can be obtained as follows:

$$
r=\frac{k+e \theta}{2 \varphi} .
$$

The Hessian matrix of $\pi_{m}$ with respect to $q$ and $e$ is as follows:

$$
H^{D}=\left[\begin{array}{cc}
-2 & \sigma \\
0 & \frac{1}{2}\left(\sigma^{2}-4\right)
\end{array}\right] .
$$

Since $-2<0$ and $\left|H^{D}\right|=4-\sigma^{2}$, when $\sigma \in[0,2)$, this Hessian matrix is negative definite, and the manufacturer's profit function is concave. There is production quantity $q^{*}$ and eco-innovation effort $e^{*}$ that enable the manufacturer to obtain the maximum profit.

Then the first-order partial derivatives of $\pi_{m}$ is found with respect to $q$ and $e$, respectively, as follows:

$$
\left\{\begin{array}{l}
\frac{\partial \pi_{m}}{\partial e}=-2 e+q \sigma \\
\frac{\partial \pi_{m}}{\partial q}=1-c+\frac{1}{2} q\left(\sigma^{2}-4\right) .
\end{array}\right.
$$

Based on the first-order conditions, we obtain the manufacturer's equilibrium solutions $q^{*}$ and $e^{*}$ as follows:

$$
\begin{aligned}
& q^{*}=\frac{2(1-c)}{4-\sigma^{2}}, \\
& e^{*}=\frac{(1-c) \sigma}{4-\sigma^{2}} .
\end{aligned}
$$

Substituting $e^{*}$ into formula (3), the optimal recycling ratio of the recycler can be obtained as follows:

$$
r^{*}=\frac{(1-c) \theta \sigma+k\left(4-\sigma^{2}\right)}{2\left(4-\sigma^{2}\right) \varphi} .
$$

Substituting $q^{*}, e^{*}$, and $r^{*}$ into the profit function of the manufacturer and the recycler, the maximum profits of the manufacturer and the recycler can be obtained as follows:

$$
\begin{aligned}
& \pi_{m}^{*}=\frac{(1-c)^{2}}{4-\sigma^{2}}, \\
& \pi_{r}^{*}=\frac{(1-c)\left((1-c) \theta \sigma+k\left(4-\sigma^{2}\right)\right)^{2}}{2\left(4-\sigma^{2}\right)^{3} \varphi} .
\end{aligned}
$$

Proposition 1. The production quantity and eco-innovation effort of the manufacturer increase with the increase in the sensitivity of production costs to eco-innovation effort $\sigma$; the recycling ratio of recyclers increases with the increase in recycling efficiency $\theta$ and with the increase and decrease in recycling difficulty $\varphi$.

When eco-innovation brings more effective production cost reduction (that is, $\sigma$ larger), the manufacturer hopes to provide more products to the market. At the same time, the manufacturer hopes to invest more eco-innovation efforts. The greater the difficulty of recycling, the higher the unit recycling cost of the recycler, the lower the profit per unit of recycled products, the lower the recycling enthusiasm of the recycler, and the lower the recycling ratio of the recycler. With the increase in recycling benefits, the profit per unit of recycled products increases, and the recycling ratio increases.

Proposition 2. The optimal profit of the manufacturer increases with the increase in the sensitivity of production costs to eco-innovation effort $\sigma$; the optimal profit of the recycler increases with the increase of $\theta$ and $\sigma$ and decreases with the increase of $\varphi$.

From Proposition 1, when the sensitivity of production cost to eco-innovation effort $\sigma$ increases, it means that the unit production cost of the products decreases, and the manufacturer's optimal ecological innovation effort and production quantity increase accordingly, thereby making the manufacturer's optimal profit increase. In addition, when the recycling benefit $\theta$ increases, the unit recycling profit becomes larger, and the total profit of the recycler becomes larger. When the recycling difficulty $\varphi$ increases, it means that the recycling costs of the recycler increase, and the proportion of recycling decreases, which will have a negative impact on the profits of the recycler. Finally, when the sensitivity of production costs to eco-innovation effort $\sigma$ increases, production quantity and eco-innovation effort of the manufacturer increase, and the recycling ratio of the recycler increases, which in turn increases the optimal profit of the recycler.

3.2. CSR Model. Following the economic assumption [53], social welfare is embodied by consumer surplus. Consumer surplus is as follows: 
TABle 1: Notations and definitions.

\begin{tabular}{|c|c|}
\hline Notation & Definitions \\
\hline \multicolumn{2}{|r|}{ Decision variables } \\
\hline$e$ & Eco-innovation effort \\
\hline$q$ & Production quantity \\
\hline$r$ & Recycling ratio \\
\hline \multicolumn{2}{|r|}{ Parameters } \\
\hline$c_{e}=e^{2}$ & The manufacturer invest in eco-innovation costs \\
\hline$c$ & Unit production cost in the absence of eco-innovation \\
\hline$c_{m}=c-\sigma e$ & Unit production cost, where the parameter $\sigma$ measures the sensitivity of production cost to eco-innovation effort \\
\hline$p=1-q$ & \multirow{2}{*}{$\begin{array}{l}\text { Selling price } \\
\text { Unit recovery income in the absence of eco-innovation }\end{array}$} \\
\hline$k$ & \\
\hline$\varphi$ & \multirow{2}{*}{$\begin{array}{l}\text { Recycling difficulty, measuring the sensitivity of unit recycling cost to the recycling rate } \\
\text { Recycling benefit, measuring the unit benefit that manufacturer's unit eco-innovation effort brings to the recycler }\end{array}$} \\
\hline$\theta$ & \\
\hline \multicolumn{2}{|r|}{ Superscript/subscripts } \\
\hline$\pi^{i}, U^{i}$ & \multirow{2}{*}{$\begin{array}{l}\text { The optimal solutions for different models }\left(i=*, c^{*}, f^{*}\right) \\
\text { Profit (utility) for the manufacturer }(j=m) \text { and the recycler }(j=r)\end{array}$} \\
\hline$\pi_{i}, U_{j}$ & \\
\hline
\end{tabular}

$$
\mathrm{CS}=\int_{p \min }^{p \max } q \mathrm{~d} q=\frac{q^{2}}{2} .
$$

Manufacturers with CSR will pay attention to a certain degree of consumer surplus while pursuing their own profits. Assuming that the social responsibility coefficient of a manufacturing company is $\mu(0<\mu<1)$, the manufacturer's decision function includes both profit and a certain degree of social welfare, that is, the utility of the manufacturer is as follows:

$$
\begin{aligned}
U_{m} & =\pi_{m}+\mu \mathrm{CS} \\
& =(1-q-c+\sigma e) q-e^{2}+\mu \frac{q^{2}}{2} .
\end{aligned}
$$

The profit function of the recycler is the same as the basic model. According to the reverse solution method, the optimal recycling ratio of the recycler is first obtained as follows:

$$
r^{c^{*}}=\frac{k+e^{c^{*}} \theta}{2 \varphi}
$$

The Hessian matrix of $U_{m}^{c}$ with respect to $q$ and $e$ is as follows:

$$
H^{D}=\left[\begin{array}{cc}
-2 & \sigma \\
0 & \mu-2+\frac{\sigma^{2}}{2}
\end{array}\right] .
$$

Because $-2<0$ and $\left|H^{D}\right|=\left(4-\sigma^{2}-\mu\right) / 2$, when $\sigma \in(0, \sqrt{4-\mu})$, the Hessian matrix is negative definite; at this time, there is optimal production quantity $q^{c^{*}}$ and ecoinnovation effort $e^{c^{*}}$ that enable the manufacturer to obtain the maximum profit.

The first-order partial derivatives of $U_{m}^{c}$ with respect to $q$ and $e$ are calculated as follows:

$$
\left\{\begin{array}{l}
\frac{\partial U_{m}^{c}}{\partial e}=-2 e+q \sigma \\
\frac{\partial U_{m}^{c}}{\partial q}=1-c+q\left(\mu-2+\frac{\sigma^{2}}{2}\right) .
\end{array}\right.
$$

Based on the first-order condition, we obtain the manufacturer's equilibrium solutions $q^{c^{*}}$ and $e^{c^{*}}$ as follows:

$$
\begin{aligned}
& q^{c^{*}}=\frac{2(c-1)}{4-2 \mu-\sigma^{2}}, \\
& e^{c^{*}}=\frac{(1-c) \sigma}{4-2 \mu-\sigma^{2}} .
\end{aligned}
$$

The optimal recycling ratio of the recycler in this mode is as follows:

$$
r^{c^{*}}=\frac{(1-c) \theta \sigma+\left(4-\sigma^{2}-2 \mu\right) k}{2\left(4-\sigma^{2}-2 \mu\right) \varphi}
$$

Substituting $q^{c^{*}}, e^{c^{*}}$, and $r^{c^{*}}$ into the formulas (1), (2), and (10), the optimal utility and profit of manufacturer and recycler can be obtained as follows:

$$
\begin{aligned}
U_{m}^{c^{*}} & =\frac{(1-c)^{2}}{4-2 \mu-\sigma^{2}}, \\
\pi_{m}^{c^{*}} & =\frac{(c-1)^{2}\left(4-4 \mu-\sigma^{2}\right)}{\left(\sigma^{2}+2 \mu-4\right)^{2}}, \\
\pi_{r}^{c^{*}} & =\frac{(c-1)\left((c-1) \theta \sigma+k\left(\sigma^{2}+2 \mu-4\right)\right)^{2}}{2\left(\sigma^{2}+2 \mu-4\right)^{3} \varphi} .
\end{aligned}
$$

To make the calculation results meaningful, it is necessary to ensure that $\mu \in\left(0,\left(4-\sigma^{2}\right) / 2\right)$, that is, if the manufacturer's social responsibility ratio is small, the profit of the manufacturer and the recycler is positive. Otherwise, it 
will harm the interests of the enterprise and fail to realize the sustainable operation of the enterprise.

Proposition 3. Under this model, production quantity $q^{c^{*}}$, eco-innovation effort $e^{c^{*}}$, and recycling ratio $r^{c^{*}}$ all increase with the increase of the CSR coefficient $\mu$. If the manufacturer assumes the CSR, the production quantity, eco-innovation effort, and recycling ratio are all greater than the optimal decision-making volume under the basic model.

When the manufacturer assumes more CSR, it means that while the company is making profits, it must create more welfare for the society, increase product production, and invest more eco-innovation effort, and the proportion of product recycling by the recycler will continue to increase. Therefore, products production, eco-innovation effort, and recycling ratio are all greater than the basic model.

Proposition 4. As the assumed CSR coefficient increases within a reasonable range, the utility of the manufacturer will increase; the optimal profit of the manufacturer itself and the recycler will decline; and the manufacturer's own profit will decline faster.

From Proposition 3, it can be seen that if the CSR coefficient $\mu$ undertaken by the manufacturer increases, the production quantity $q^{c^{*}}$ and eco-innovation effort $e^{c^{*}}$ both increase. As the manufacturer undertakes CSR, they can increase their own brand effect and corporate image, thereby increasing the utility of the manufacturer, but the more responsible the social welfare, the profit of both the manufacturer and the recycler will decrease. Although the profit of the manufacturer and the recycler will be negatively affected, the manufacturer is more affected, so the manufacturer will carefully consider the CSR coefficient. If manufacturer considers their own utility and long-term development, they will sacrifice their own profits to assume more social responsibilities. In this case, the recycling ratio and profits of the recycler will be damaged, and the recycling enthusiasm and willingness of the recycler will be gradually reduced.

Proposition 5. $\pi_{m}^{c^{*}}<\pi_{m}^{*}<U_{m}^{c^{*}}, \pi_{r}^{c^{*}}<\pi_{r}^{*}$, that is, when the manufacturer assumes CSR, its own utility increases, but the profit is less than the optimal profit without CSR, and the profit of the recycler is damaged by the manufacturer's CSR.

When the manufacturer assumes CSR, it will create a good corporate image and increase the company's brand effect, thereby increasing the manufacturer's utility. But, after assuming CSR, the amount of decisions made by the manufacturer and the recycler is relatively small, which damages the best profits of both parties themselves. For the long-term development of the enterprise, the manufacturer should pay more attention to improving the utility of their own enterprises. But, as the profits of the recycler decline after the manufacturer assumes the CSR, the recycler will have a strong sense of unfairness.

3.3. CSR and Fairness Concerns Model. The recycler pays attention not only to their own profits but also to the profit gap with the manufacturer. The greater the profit gap, the stronger the fairness concerns of recycler, which will usually affect the decision-making process of the manufacturer and the recycler. Using the fairness concerns model of $[32,54]$ for reference, the utility function of the recycler is as follows:

$$
U_{r}^{f}=\pi_{r}-\eta\left(\pi_{m}-\pi_{r}\right)
$$

where $\eta$ is the fairness concerns coefficient of the recycler. As $\eta$ increases, the recycler pays more and more attention to the profit gap. The utility function of the recycler can be simplified as follows:

$$
U_{r}^{f}=(1+\eta) \pi_{r}-\eta \pi_{m}
$$

According to the inverse solution method, due to $\left(\partial^{2} U_{r}^{f} / \partial r^{2}\right)=-2 q \varphi(1+\theta)<0$, there is an optimal recycling ratio $r^{f^{*}}$ to maximize the utility of the recycler. In this case, the manufacturer's utility function and the manufacturer's decision variables have not changed, which is as follows:

$$
\begin{aligned}
& r^{f^{*}}=\frac{k+e^{f *} \theta}{2 \varphi}, \\
& q^{f^{*}}=q^{c^{*}}=\frac{2(1-c)}{4-2 \mu-\sigma^{2}}, \\
& e^{f^{*}}=e^{c^{*}}=\frac{(1-c) \sigma}{4-2 \mu-\sigma^{2}} .
\end{aligned}
$$

Substituting $e^{f^{*}}$ into the formula (19), the optimal recycling ratio of the recycler is as follows:

$$
r^{f^{*}}=\frac{-4 k+2 k \mu-\theta \sigma+c \theta \sigma+k \sigma^{2}}{2\left(\sigma^{2}+2 \mu-4\right) \varphi}
$$

The optimal utilities of the manufacturer and the recycler are as follows:

$$
\begin{aligned}
U_{m}^{f^{*}} & =\frac{(1-c)^{2}}{4-2 \mu-\sigma^{2}}, \\
U_{r}^{f^{*}} & =\frac{(1-c)\left((1+\eta)\left((1-c) \theta \sigma-k\left(-4+2 \mu+\sigma^{2}\right)\right)^{2}-2 \eta(1-c)\left(-4+2 \mu+\sigma^{2}\right)\left(-4+4 \mu+\sigma^{2}\right) \varphi\right)}{2\left(4-2 \mu-\sigma^{2}\right)^{3} \varphi} .
\end{aligned}
$$


Proposition 6. The utility of the recycler increases with the increase of the fairness concerns coefficient $\eta$ when $\mu \in\left(0,\left(4-\sigma^{2}\right) / 4\right)$. The utility of the recycler decreases with the increase of the fairness concerns coefficient $\eta$ when $\mu \in\left(\left(\left(4-\sigma^{2}\right) / 4\right), t\left(\left(4-\sigma^{2}\right) / 2\right)\right)$.

When the manufacturer undertakes less CSR, the recycler should adopt a lower fairness concerns coefficient. Conversely, if the manufacturer undertakes more CSR, the recycler will pay more attention to the profit gap between itself and the manufacturer. This is also true in practice. When the manufacturer assumes more social responsibilities, it will form a better corporate image and will correspondingly influence and increase the willingness of partners to cooperate, thereby reducing the fairness concern coefficient of the partners.

Proposition 7. When the recycler considers fairness concerns, there is no change in the comparison between the manufacturer's optimal utility and the CSR model, that is, $U_{m}^{c^{*}}=U_{m}^{f^{*}}>U_{m}^{*}$, and the utility of the recycler has changed, and the specific changes are as follows:

(1) When $k^{2}>4(1-c) \varphi, U_{r}^{f^{*}}>U_{r}^{*}>U_{r}^{c^{*}}$.

(2) When $k^{2}<4(1-c) \varphi$,

$$
\left\{\begin{array}{l}
U_{r}^{f^{*}}>U_{r}^{*}>U_{r}^{c^{*}} \\
\frac{\left(k \theta \sigma(1-c)^{2}+k^{2}\left(c-1+3\left((1-c)^{2}\left(\sigma^{2}-4\right) \varphi+A\right)\right)\right)}{2(1-c)\left(4(1-c) \varphi-k^{2}\right)}<\mu<\frac{4-\sigma^{2}}{2} \\
U_{r}^{c *}>U_{r}^{*}>U_{r}^{f *}, \\
0<\mu<\frac{\left(k \theta \sigma(1-c)^{2}+k^{2}\left(c-1+3\left((1-c)^{2}\left(\sigma^{2}-4\right) \varphi+A\right)\right)\right)}{2(1-c)\left(4(1-c) \varphi-k^{2}\right)}
\end{array}\right.
$$

where $A=\sqrt{(1-c)^{4} \varphi\left((4-4 c) \theta \sigma^{2}-2 k \theta \sigma\left(\sigma^{2}-4\right)+\right.}$ $\left.\left(\sigma^{2}-4\right)^{2} \varphi\right)$.

When the recycler considers fairness concerns, the manufacturer's utility has not changed, and both are greater than the utility under the basic model. Therefore, the recycler's concern for fairness has not changed the manufacturer's situation and business decisions. As for the recycler itself, when the recycling revenue per unit product is large, the recyclers' utility is greater than the utility under the basic model and the CSR model. Under this circumstance, when the manufacturer assumes more CSR, the profit of the recycler will suffer. At this time, the recycler should pay more attention to the profit gap with the manufacturer. If the manufacturer undertakes less CSR, the recycler will be the most effective under the basic model. At this time, the recycler does not need to consider fairness concerns. If the manufacturer considers the long-term development of their own enterprises, they will choose to undertake CSR. At the same time, in order to maintain the continuous development of the entire supply chain, the manufacturer should also pay attention to the effectiveness and willingness of their partners to cooperate.

\section{Stability Analysis of the CSR and Fairness Concerns Model}

In the above static game, the equilibrium solution presented depends on the complete rationality of the participants. In other words, decision-makers need complete information about the market to make perfect decisions. In practice, due to the lack of necessary information, the manufacturer cannot implement this perfect strategy under bounded rationality, and such a profit maximization problem is often difficult to be solved. But the manufacturer can adjust strategy through learning and imitation based on their own experience to obtain greater utility. Therefore, we introduce a dynamic model to describe the evolution of the manufacturer's decision-making process. Comprehensive Proposition 7 shows that in most cases, the manufacturer and the recycler can achieve a win-win situation under the CSR and fairness concerns model, which can maximize the total utility of the supply chain. Therefore, it is more meaningful to analyze the dynamic decision-making process under the CSR and fairness concerns model next.

In this dynamic Stackelberg game, the manufacturer makes a decision in period $t+1$ based on the results of period $t$, that is, the manufacturer updates the eco-innovation effort and production quantity of products in period $t+1$ according to the marginal profit in period $t$. This mechanism is called the long-term gradient adjustment mechanism, which is implemented based on the estimation of the marginal utility $\left(\partial U_{m}^{f} / \partial e\right)$ and $\left(\partial U_{m}^{f} / \partial q\right)$ in discrete time periods on the basis of the principle of local optimality. The recycler can optimally respond to the manufacturer's decision in each time period. Note that in this dynamic system (25), we assume that the manufacturer is the decision-maker with bounded rationality, and the recycler is completely rational. This is because the manufacturer is upstream of the supply chain, and the decision-making environment they face is more complicated, and recycler has 
a time advantage in decision-making compared with the manufacturer. Therefore, the manufacturer with bounded rationality needs to adjust strategies based on local optimization, while the recycler with complete rationality makes decisions on the recycling ratio based on the optimal response function.

To characterize the adjustment process, the myopic adjustment mechanism (e.g., $[55,56])$ at each time period $t$ is introduced as follows:

$$
\left\{\begin{array}{l}
q(t+1)=q(t)+\alpha_{q} \cdot q(t) \frac{\partial U_{m}^{f}(t)}{\partial q(t)}, \\
e(t+1)=e(t)+\alpha_{e} \cdot e(t) \frac{\partial U_{m}^{f}(t)}{\partial e(t)},
\end{array}\right.
$$

where $\alpha_{q}$ and $\alpha_{e}$ denote the adjustment speeds of the manufacturer's production and the eco-innovation effort of the manufacturer with respect to the marginal utility, respectively. This means that manufacturer will adjust their decisions based on estimates of profit margins over discrete time periods. In each time period, once the manufacturer has determined the production quantity and ecological innovation effort, the recycler will determine the optimal recycling ratio under static expectations to maximize its utility. Therefore, the optimal recycling ratio of recycler can be determined as $r(q(t), e(t))=((k+e(t) \theta) / 2 \varphi)$.

So the dynamic decision model is as follows:

$$
\left\{\begin{array}{l}
q(t+1)=q(t)+\alpha_{q} q(t)(1-c+(\mu-2) q(t)+e(t) \sigma), \\
e(t+1)=e(t)+\alpha_{e} e(t)(-2 e(t)+q(t) \sigma) .
\end{array}\right.
$$

We now use analytical methods and numerical methods to analyze the stability of the repeated dynamic game system, respectively. When $q(t+1)=q(t)=q^{*}$ and $e(t+1)=e(t)=e^{*}$, dynamic system (25) reaches an equilibrium state. The equilibrium points can be solved as $E_{1}(0,0), \quad E_{2}((1-c) /(2-\mu), 0), \quad E_{3}\left(2(1-c) /\left(4-\sigma^{2}\right.\right.$ $\left.-2 \mu), \sigma(1-c) /\left(4-\sigma^{2}+2 \mu\right)\right)$. Among them, $E_{1}$ and $E_{2}$ are the boundary equilibrium points, and $E_{3}$ is the only internal equilibrium point of dynamic system (25). In a practical sense, the manufacturer will never set the production quantity and eco-innovation effort to zero. In order to discuss the local stability of the equilibrium point $E_{3}$, we introduce the Jacobian matrix of dynamic system (25) at point $E_{3}$ as follows:

$$
J\left(E_{3}\right):=J\left(q^{*}(t), e^{*}(t)\right)=\left[\begin{array}{cc}
1+\alpha_{q}\left(1-c+2(\mu-2) q^{*}(t)+e^{*}(t) \sigma\right) & \alpha_{q} q^{*}(t) \sigma \\
\alpha_{e} e^{*}(t) \sigma & 1+\alpha_{e}\left(-4 e^{*}(t)+q^{*}(t) \sigma\right)
\end{array}\right] .
$$

Substitute in $E_{3}\left(\left(2(1-c) /\left(4-\sigma^{2}-2 \mu\right)\right),(\sigma(1-c) /(4-\right.$ $\left.\left.\sigma^{2}+2 \mu\right)\right)$ ) to get

$$
J\left(E_{3}\right)=\left[\begin{array}{cc}
1+\frac{2 \alpha_{q}(c-1)(\mu-2)}{\sigma^{2}+2 \mu-4} & \frac{2 \alpha_{q}(c-1) \sigma}{\sigma^{2}+2 \mu-4} \\
\frac{\alpha_{e}(c-1) \sigma^{2}}{\sigma^{2}+2 \mu-4} & 1-\frac{2 \alpha_{e}(c-1) \sigma}{\sigma^{2}+2 \mu-4}
\end{array}\right] .
$$

For the sake of simplicity, we introduce the Jury criterion to judge the stability of the Nash equilibrium point. The twodimensional Jury criterion is formulated as follows:

$$
\left\{\begin{array}{l}
1-\operatorname{Tr}(J)+\operatorname{Det}(J)>0 \\
1+\operatorname{Tr}(J)+\operatorname{Det}(J)>0 \\
1-\operatorname{Det}(J)>0
\end{array}\right.
$$

where $\operatorname{Tr}$ and Det represent the trace and determinant of the Jacobian matrix $J\left(E_{3}\right)$, respectively. In the Jury criterion, the three conditions correspond to the transcritical bifurcation curve, flip bifurcation curve, and Neimark-Sacker bifurcation curve, respectively. If any one of them changes from inequality to equality with the other two remaining unchanged, the equilibrium will lose its stability through one of three bifurcations according to the nonlinear dynamic system theory [57].
Proposition 8 presents the conditions for the local stability of the dynamic game equilibrium point $E_{3}$.

Proposition 8. The stability of the Nash equilibrium point $E_{3}$ needs to satisfy the following conditions:

$$
\left\{\begin{array}{l}
0<\alpha_{q}<\frac{2\left(\sigma^{2}+2 \mu-4+\alpha_{e} \sigma(1-c)\right)}{(c-1)\left(4-2 \mu+\alpha_{e} \sigma(c-1)\right)}, \\
0<\alpha_{e}<\frac{\alpha_{q}(\mu-2)}{\sigma-\alpha_{q}(c-1) \sigma} .
\end{array}\right.
$$

4.1. Influence of Parameter Changes on the Stable Area of Dynamic System (25). For a better understanding of the complex behavior in the dynamic decision system, we perform numerical simulations in the following. We fix the parameters as $c=0.5, \mu=0.2, \sigma=1, k=1.5, \varphi=3, \theta=0.2$, $\eta=0.2, q_{0}=0.3$, and $e_{0}=0.1$. With the values of these parameters, the unique equilibrium solution of the model given in the previous section can be calculated as $q^{*}=0.385, e^{*}=0.192$.

Figure 1 shows the stable region of the dynamic system. We can see from Figure 1 that dynamic system (25) will be stable only when the adjustment parameters $\alpha_{q}$ and $\alpha_{e}$ are 


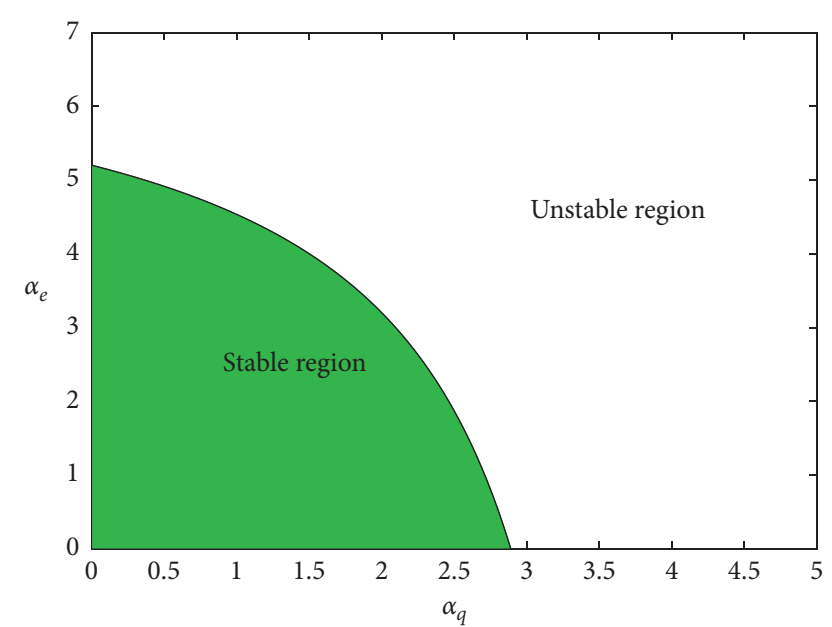

FiguRe 1: The stable region regard to $\alpha_{q}$ and $\alpha_{e}$.

small enough. Once the adjustment speed exceeds its threshold, the system (25) will lose its stability.

Figures 2 and 3 show the changes in the stable area of dynamic system (25) when $\mu$ and $\sigma$ take different values. By observing the size of the stable area in Figure 2, we can find that the larger the manufacturer's social responsibility coefficient $\mu$, the smaller the stable area of the Nash equilibrium point, and an appropriate reduction in the social responsibility coefficient $u$ can help manufacturer make decision more easily. Figure 3 shows that the change of $\sigma$ significantly affects the change of the equilibrium point, and the stable area keeps decreasing with the increase of $\sigma$. As can be seen from Figures 2 and 3, compared with $\alpha_{q}$, the influence of parameter change on adjustment speed $\alpha_{e}$ is more obvious. When manufacturers make decisions on production quantity and ecological innovation effort, they should determine the adjustment speed of the system according to the parameters reflected by the actual market conditions, so as to make dynamic system (25) in a stable state.

In this section, set the same parameter values as in the previous section, and the dynamic behavior of the dynamic system is described by $\alpha_{q}$ and $\alpha_{e}$. Figure $4(\mathrm{a})$ is the bifurcation diagram of dynamic system (25) with $\alpha_{q}$ changing when $\alpha_{e}=0.5$. When $\alpha_{q} \in(0,2.85)$, the dynamic system is stable. When $\alpha_{q}$ changes from 2.85 to 3.65 , the dynamic system has a two-period cycle. When $\alpha_{q}>3.65$, dynamic system (25) accelerates through the period-doubling bifurcation and finally enters a chaotic state. The LLE of the dynamic system is shown in Figure 4(b). When dynamic system (25) is in a stable state, the LLE is negative. When dynamic system (25) is in a chaotic state, most of the LLE is greater than zero.

In order to more clearly explain the changes of decision variables under different adjustment speeds. Figure 5 shows the time series of the decision variables of the system in different states of stability (blue dots), period-doubling bifurcation (red dots), and chaos (green dots). We can see that only in a stable system, the manufacturer can have the only optimal production quantity decision.

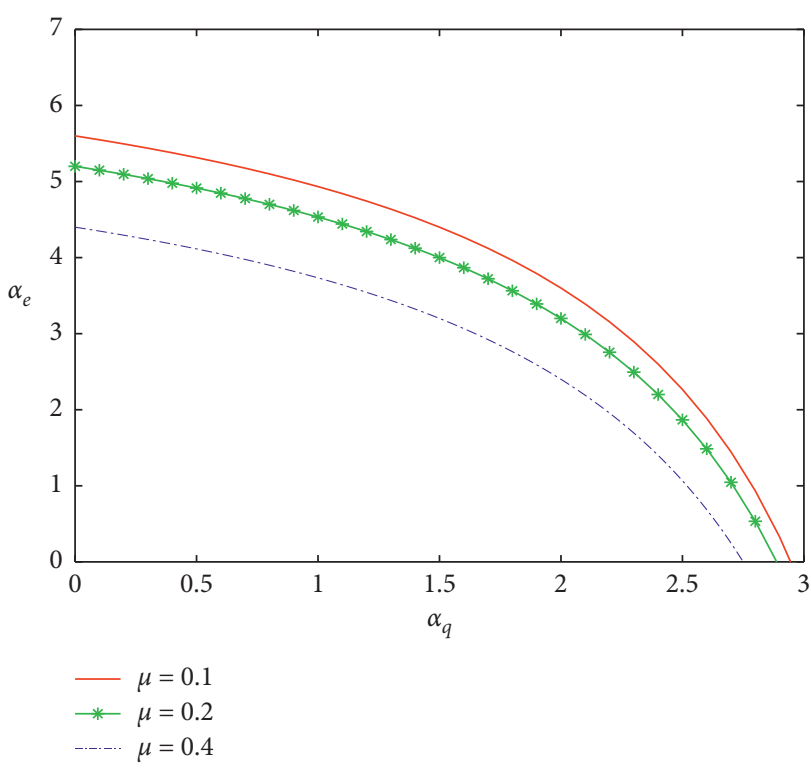

Figure 2: The evolution process of dynamic system (25) with different parameter $(\mu)$ values.

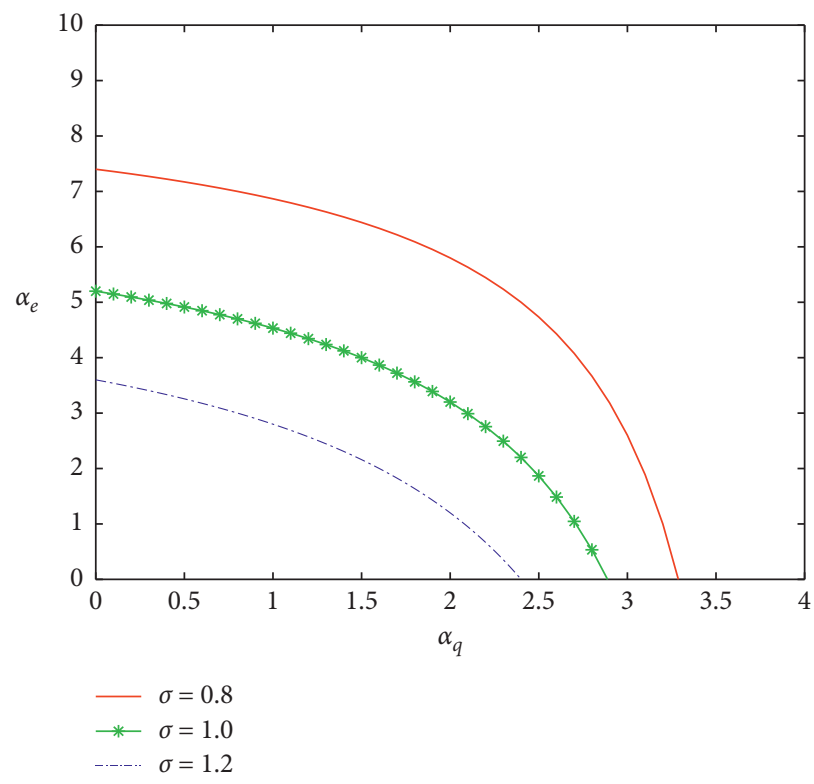

FIgURE 3: The evolution process of dynamic system (25) with different parameter $(\sigma)$ values.

Figure 6 shows the changing trend of dynamic system (25) with $\alpha_{e}$ when $\alpha_{q}=0.5$. It can be seen from Figure 6(a) that dynamic system (25) is in a stable state when $\alpha_{e}<4.95$. Then, as $\alpha_{e}$ increases, dynamic system (25) enters a bifurcation or chaos state. In addition, when $\alpha_{e}<4.95$, the LLE of dynamic system (25) is negative, indicating that dynamic system (25) can reach a steady state. Figure 7 shows the time series of the production quantity under different states of stability (blue dots), period-doubling bifurcation (red dots), and chaos (green dots). We find that only when the system is 


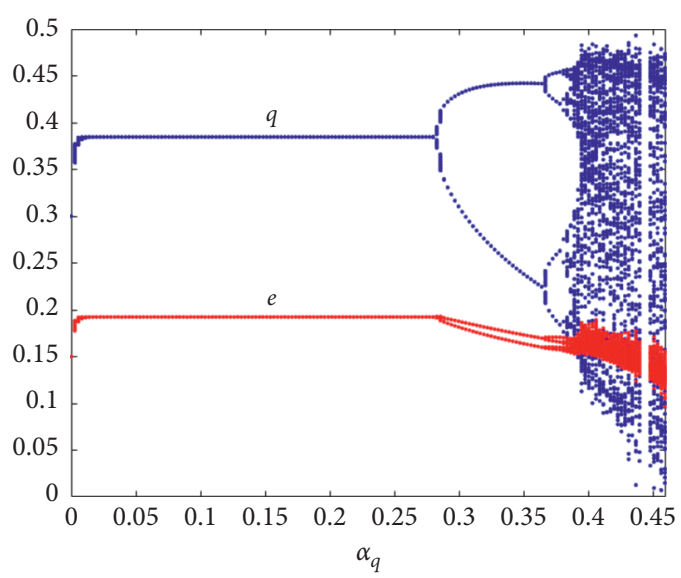

(a)

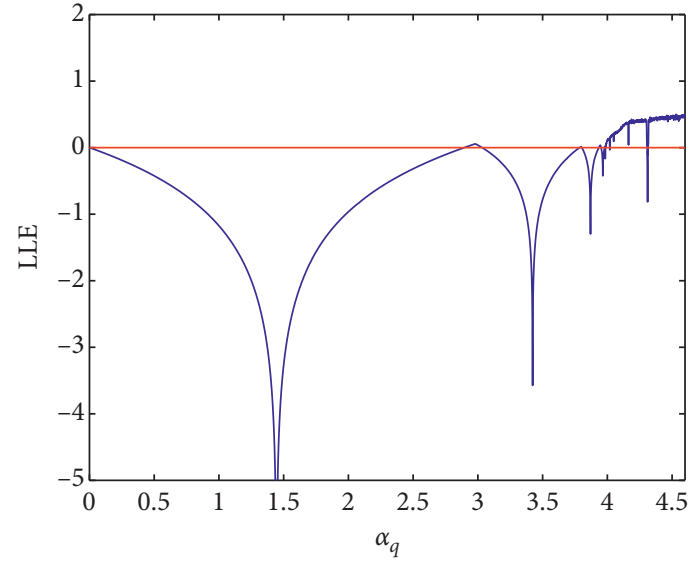

(b)

FIgUre 4: The bifurcation diagram of dynamic system (25) with respect to $\alpha_{q}$ when $\alpha_{e}=0.5$. (a) The bifurcation diagram. (b) The LLE diagram.

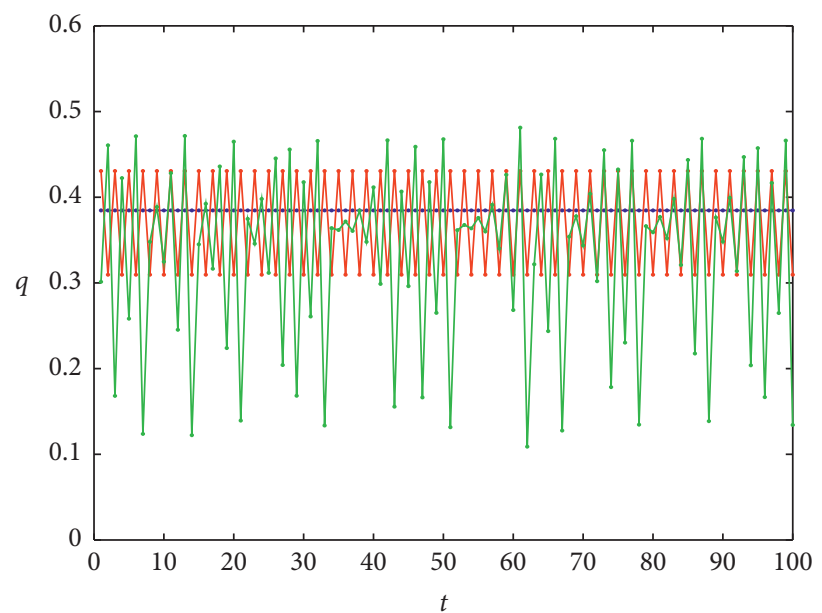

FIGURE 5: When $\alpha_{e}=0.5$, the time series of decision-making in different system states $\alpha_{q}=2, \alpha_{q}=3$, and $\alpha_{q}=4$.

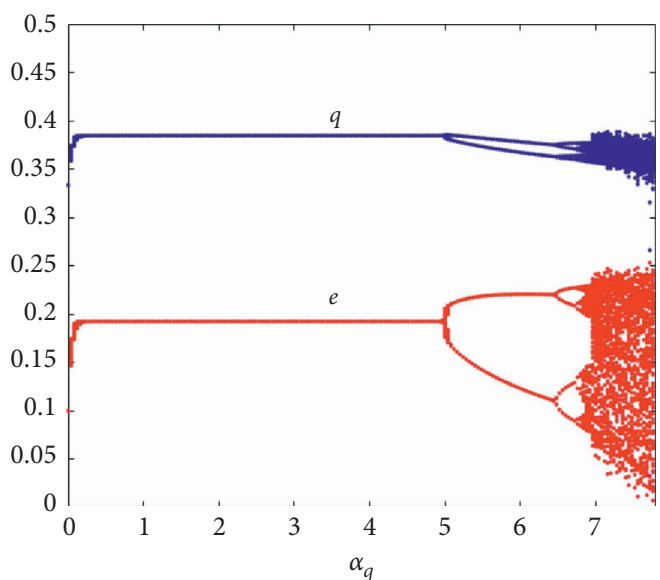

(a)

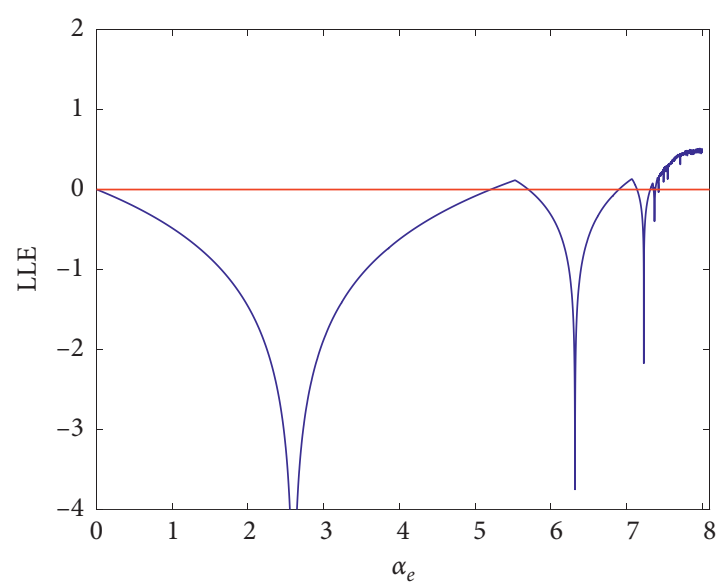

(b)

Figure 6: The bifurcation diagram of dynamic system (25) with respect to $\alpha_{e}$ when $\alpha_{q}=0.5$. (a) The bifurcation diagram. (b) The LLE diagram. 


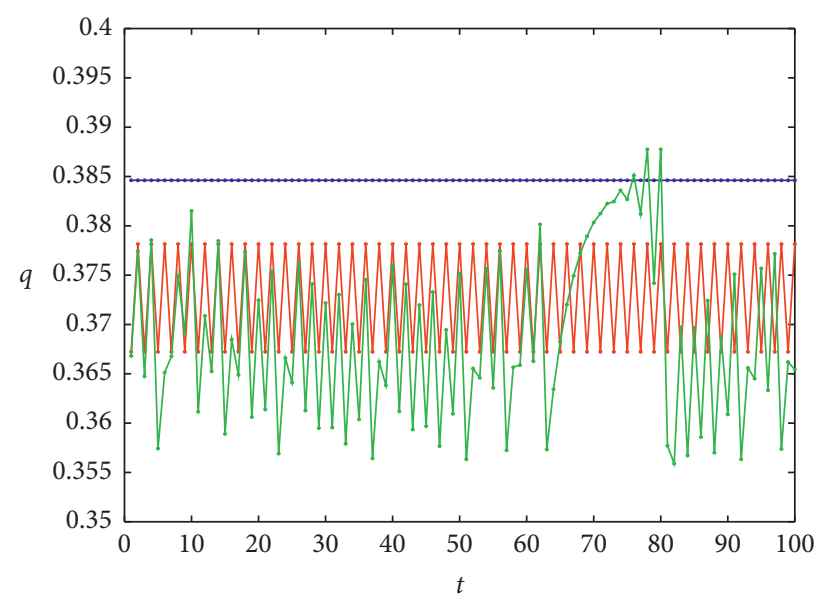

FIGURE 7: When $\alpha_{q}=0.5$, the time series of decision-making in different system states $\alpha_{e}=4, \alpha_{e}=6$, and $\alpha_{e}=7$.

stable can the manufacturer make the optimal decision continuously.

Chaos attractor is an important feature that characterizes the chaotic state of dynamic system (25). Figure 8 shows the chaotic attractor of dynamic system (25) when $\alpha_{q}=4$ and $\alpha_{e}=0.5$. In a state of chaos, manufacturers' production quantity and eco-innovation efforts are disordered. Figure 9 clearly shows how a stable system enters into a chaotic state from period-doubling bifurcation paths. From a macro perspective, the iterative trajectories appear to be regular. However, if we magnify the pictures, we can find the chaotic points forming the iterative trajectories. This irregular order is one of the most essential characteristics of a chaotic system. In order to keep the system stable, the adjustment speed should be lower than its threshold.

4.2. Global Analysis. In the previous section, the involved scope of the local analysis is confined to a small neighborhood around the equilibrium point, while the initial values of the state variables $\left(q_{0}\right.$ and $\left.e_{0}\right)$ may not belong to such a neighborhood due to the manufacturer's subjective judgment of the market under limited information at the beginning of the game. Therefore, it is necessary to conduct a global analysis of the long-term behavior of the dynamic game system. The main purpose of the global analysis is to define the range of initial values, and this method is also mentioned in [58-60]. There are three important concepts: attractors, critical curves, and basins of attraction when studying the global dynamics of two-dimensional irreversible mapping.

The basin of attraction can be used as a guide to ensure that the initial pricing strategy that belongs to the field of attraction can converge to the same attractor. In the repeated game, the attraction basin of the dynamic game system (25) is shown in Figure 10. From a realistic point of view, the dynamic process is meaningful only when $S=\left\{(q, e) \in R^{2}: q>0, e>0\right\}$. We define system $(25)$ as an irreversible map $T$, and its basin of attraction is marked in green in Figure 10. Since that system (25) is a quadratic equation of two variables, when we want to solve $(q(t), e(t))$ by $(p(t+1), e(t+1))$, there may be 0,2 , or 4 solutions. The $R^{2}$ space is divided into different regions, represented by $Z_{i}$ ( $i$ being the number of rank-1 preimages). As shown in Figure 10, the area is divided into three parts by two critical lines LC, where the symbols $Z_{0}, Z_{2}$, and $Z_{4}$ represent the 0 , 2 , and 4 solution areas, respectively. In order to obtain the critical curve $\mathrm{LC}$, we introduce the curve $\mathrm{LC}_{-1}$, which is the original image of LC under the mapping $T$, namely $T\left(\mathrm{LC}_{-1}\right)=\mathrm{LC} . \mathrm{LC}_{-1}$ belongs to the locus of points under the condition that the Jacobi an determinant of $T$ disappeared, namely,

$$
\operatorname{LC}_{-1} \subseteq\{(q, e): \operatorname{Det}(J)=0\} .
$$

Given other parameters, $\mathrm{LC}_{-1}$ can be defined as a function of $(q, e)$. We can observe that $\mathrm{LC}_{-1}$ is a hyperbola with two branches. LC is the union of the two branches of $\mathrm{LC}=T\left(\mathrm{LC}_{-1}\right)$. In Figure 10, $\mathrm{LC}_{-1}$ and $\mathrm{LC}$ are denoted by the red dotted curves and blue solid curves, respectively.

By observing Figures 10(a) and 10(c), it can be clearly seen that as the adjustment speed increases, the attractor becomes more complex, and its basin shrinks. This also proves the conclusion in Proposition 8: in order to maintain the stability of the system (25), the adjustment speed needs to be kept within the limit. Specifically, when the adjustment speed is small, the system is stable. As the adjustment speed increases, the stability of the system will be destroyed. Therefore, the attractor changes from a single value in Figure 10(a) to two values in Figure 10(b) and finally evolves into multiple values in the chaotic state in Figure 10(c).

4.3. Profit Comparison of Different States of Dynamic System (25). Changes in parameter values will obviously affect the stability of dynamic system (25). Manufacturers' decisionmaking in an unstable state is a complex issue. Therefore, we next analyze the impact of adjustment speed parameter changes on the manufacturer and the recycler. Figures 11 and 12 show the results of $q$, e, and $r$ varying with different states in the dynamic system. Through observation, we can find that the decision variables $q, e$, and $r$ have decreased in both period-doubling and chaotic states. Figure 13 shows the 


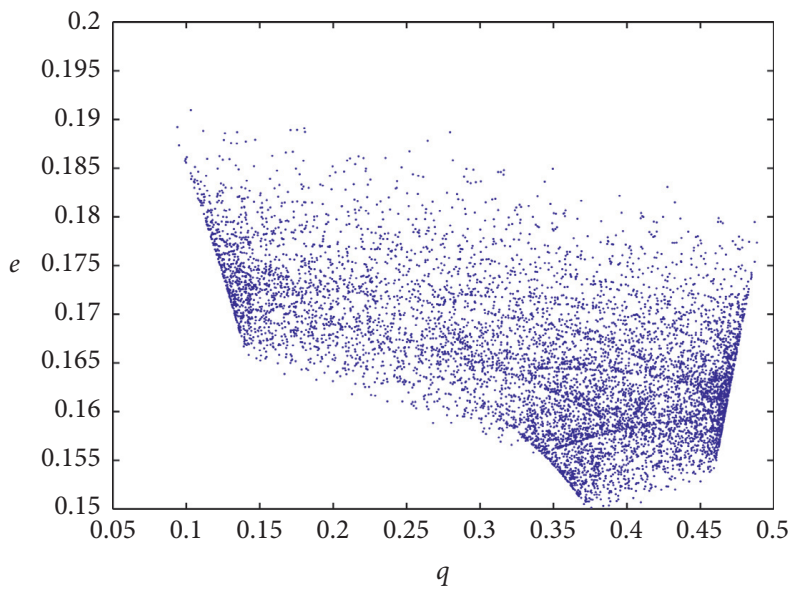

Figure 8: The chaotic attractor of dynamic system (25) when $\alpha_{q}=4$ and $\alpha_{e}=0.5$.

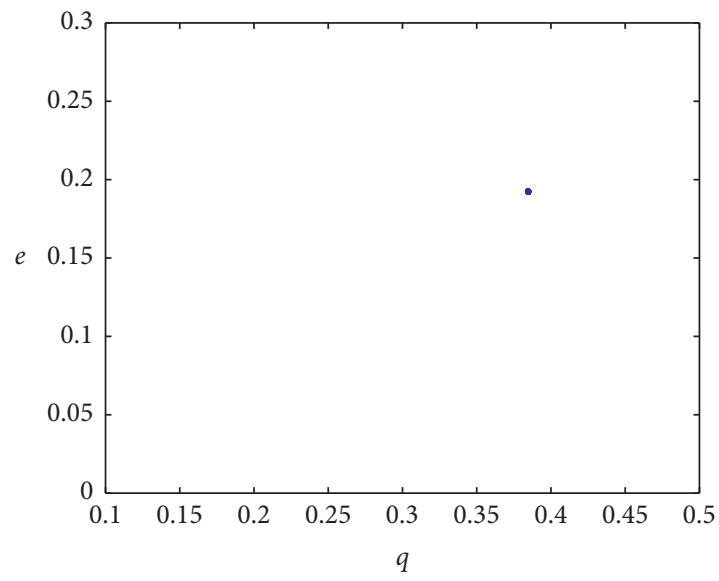

(a)

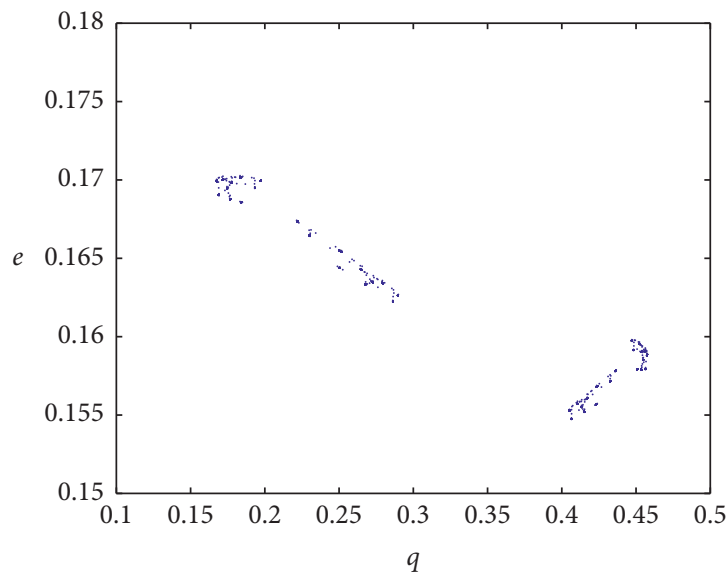

(c)

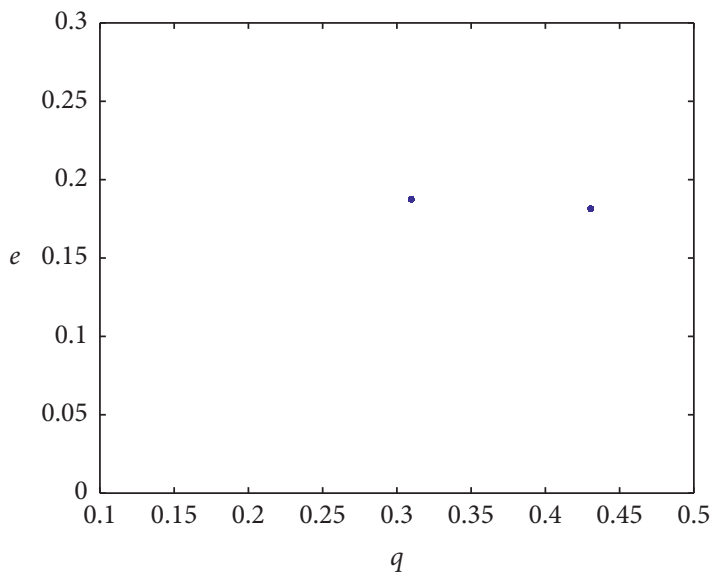

(b)

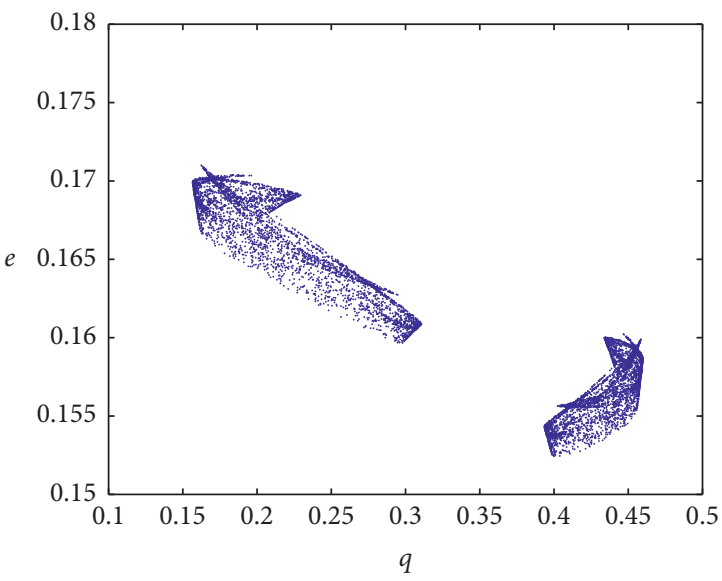

(d)

Figure 9: The chaotic attractor of dynamic system (25) changes with $\alpha_{q}$ when $\alpha_{e}=0.02$. (a) $\alpha_{q}=2, \alpha_{e}=0.5$. (b) $\alpha_{q}=3, \alpha_{e}=0.5$. (c) $\alpha_{q}=3.8, \alpha_{e}=0.5$. (d) $\alpha_{q}=3.9, \alpha_{e}=0.5$. 


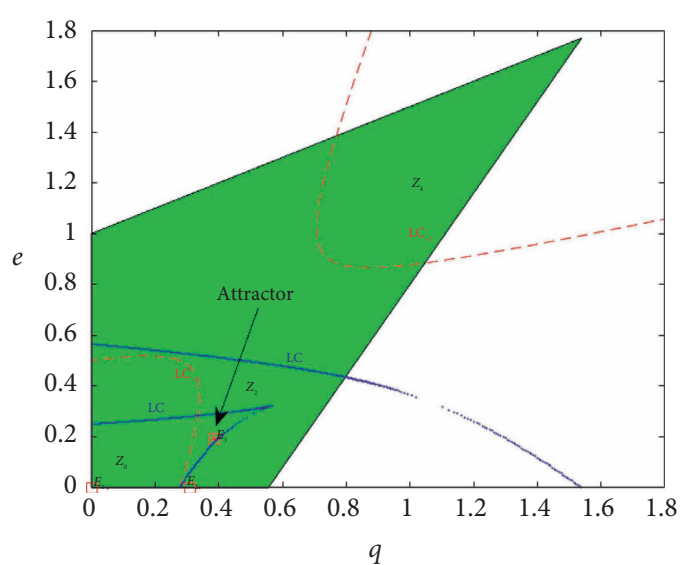

(a)

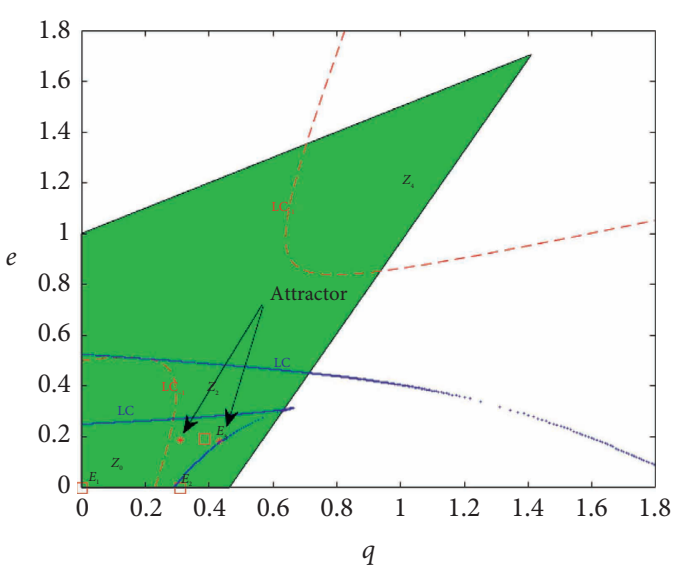

(b)

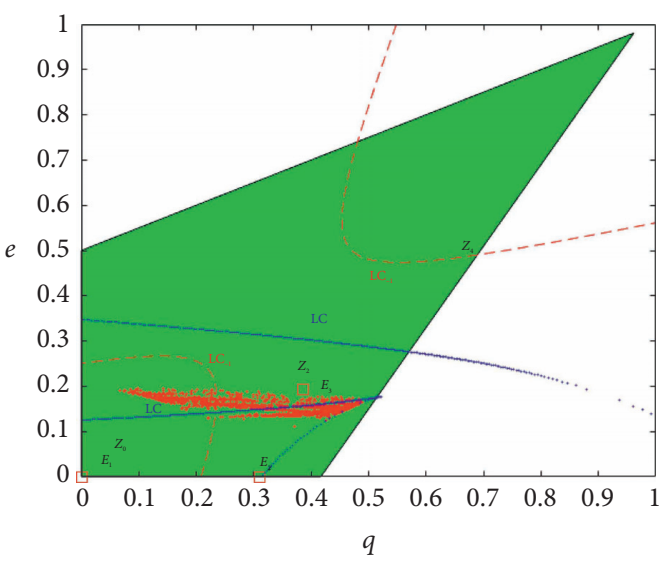

(c)

FIGURE 10: The basin of attraction and attractors. (a) $\alpha_{q}=2, \alpha_{e}=0.5$. (b) $\alpha_{q}=3, \alpha_{e}=0.5$. (c) $\alpha_{q}=4, \alpha_{e}=1$.

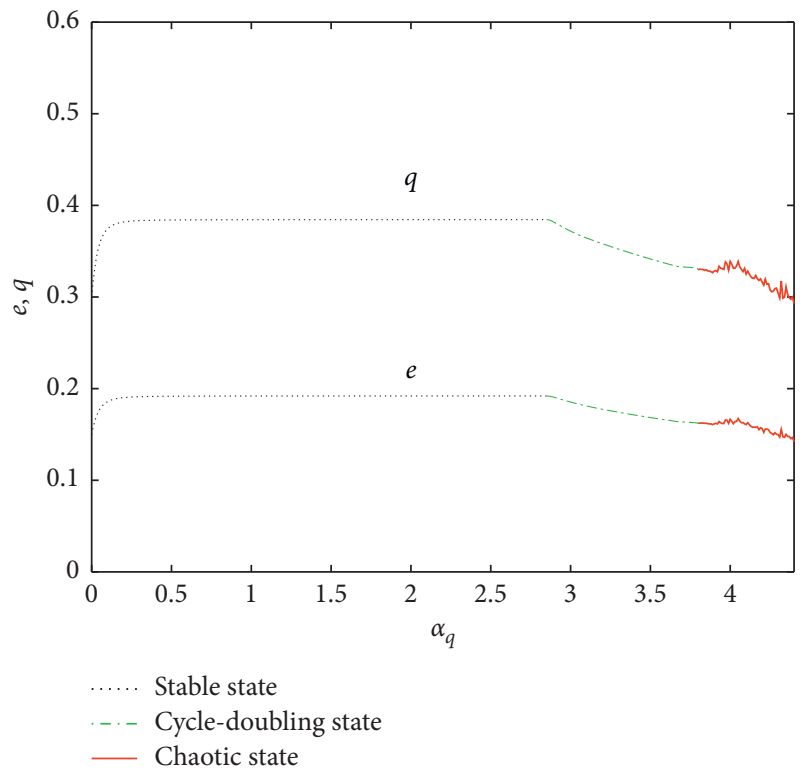

FIGURE 11: The average production quantity and eco-innovation effort of manufacturer in different states of system (25). 


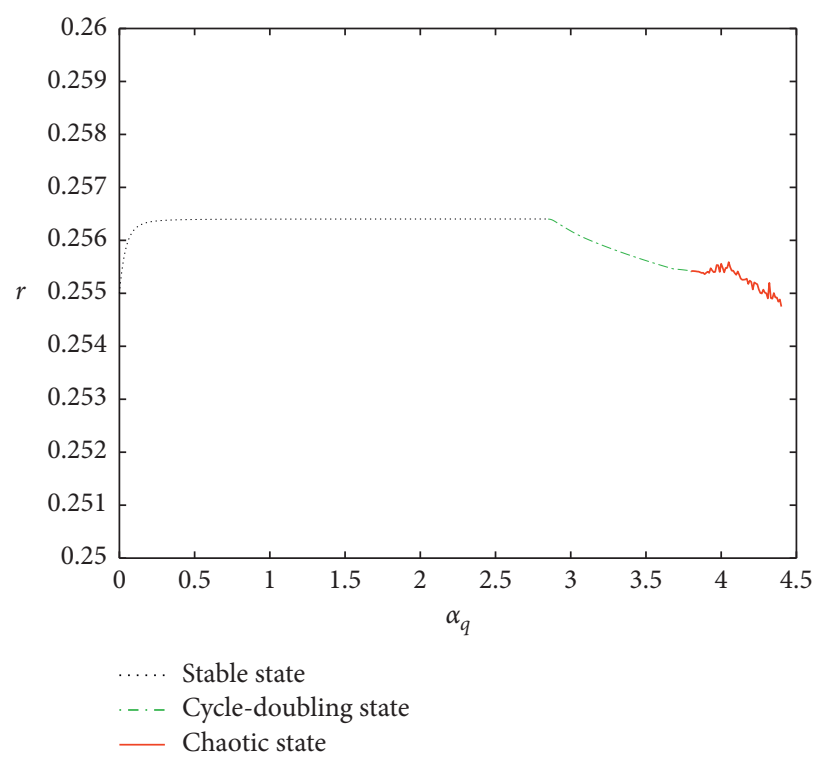

FIGURE 12: The average recycling ratio of recycler in different states of system (25).

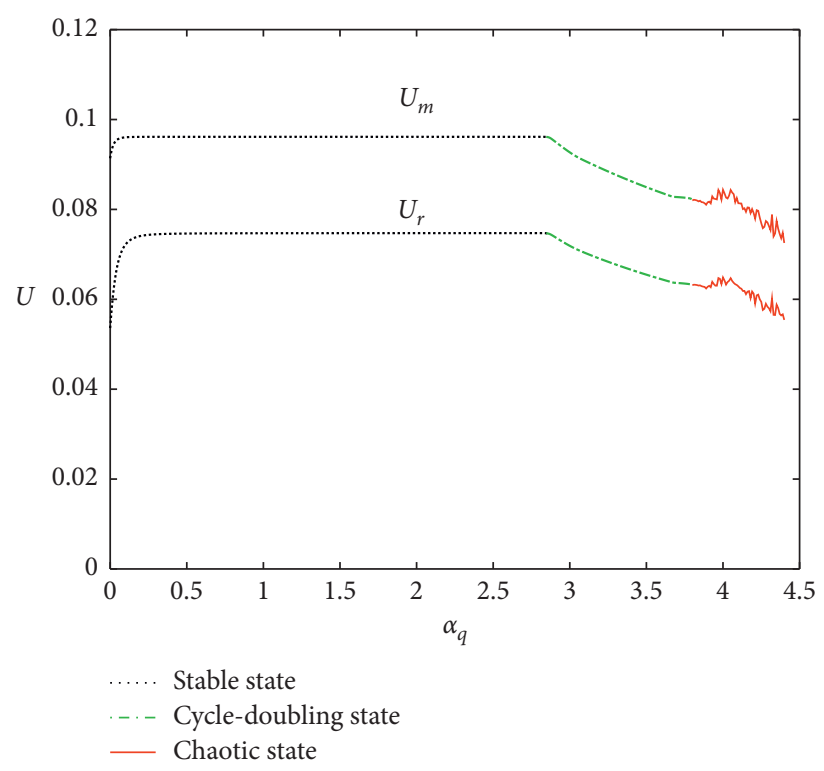

FIGURE 13: The average utility of manufacturer and recycler in different states of system (25).

results of changes in the average utility of manufacturer and recycler with the adjustment speed $\alpha_{q}$. We can see that the average utility of both manufacturer and recycler declines in the cycle-doubling, bifurcation, and chaotic state. Therefore, the unstable state has a greater negative impact on the supply chain.

\section{Chaos Control}

From the above numerical simulation, it can be seen that if the manufacturer's adjustment speed exceeds the stable area, the system will lose stability or even fall into chaos. According to the previous section, it is detrimental to the utility of the manufacturer and the recycler in an unstable state. In order to avoid this risk, it is very necessary to choose appropriate adjustment parameters to keep the system in a stable state. Scholars have proposed many methods for chaos control, such as modified straight-line stabilization method [61], time-delay feedback method [62], OGY method [63], and parameter adaptation method [64]. In this section, the delayed feedback control (DFC) method [65] is used to control the system's chaos. This control method has been widely used in many documents, such as $[55,66]$. The controlled system is given by

$$
\left\{\begin{array}{l}
q(t+1)=f\left(q(t), u_{1}(t)\right), \\
e(t+1)=f\left(e(t), u_{2}(t)\right),
\end{array}\right.
$$

where $q(t+1)$ and $e(t+1)$ are the state variables and $u_{i}(t)$ is the control signal. The specific form of the control signal is as follows: 


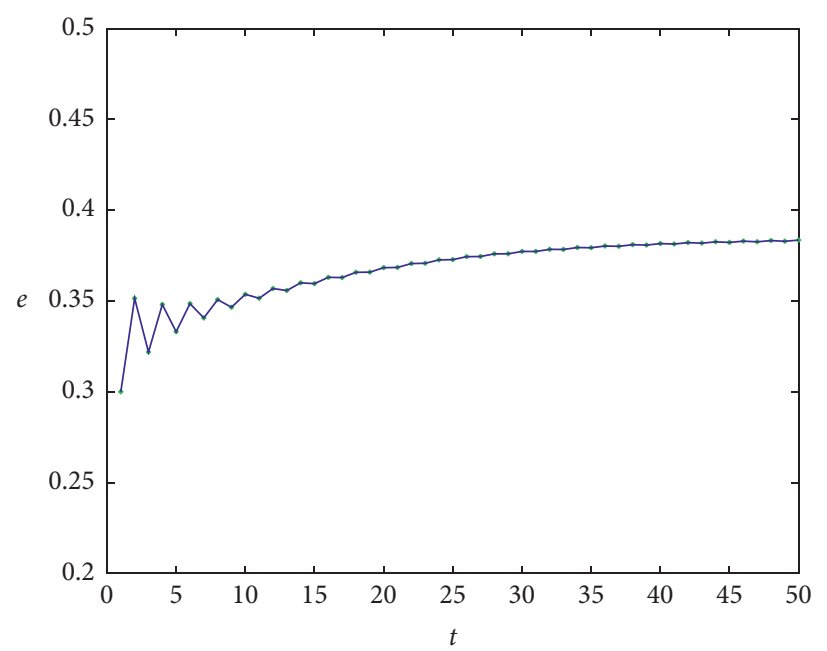

FIGURE 14: The production quantity fluctuations of the manufacturer.

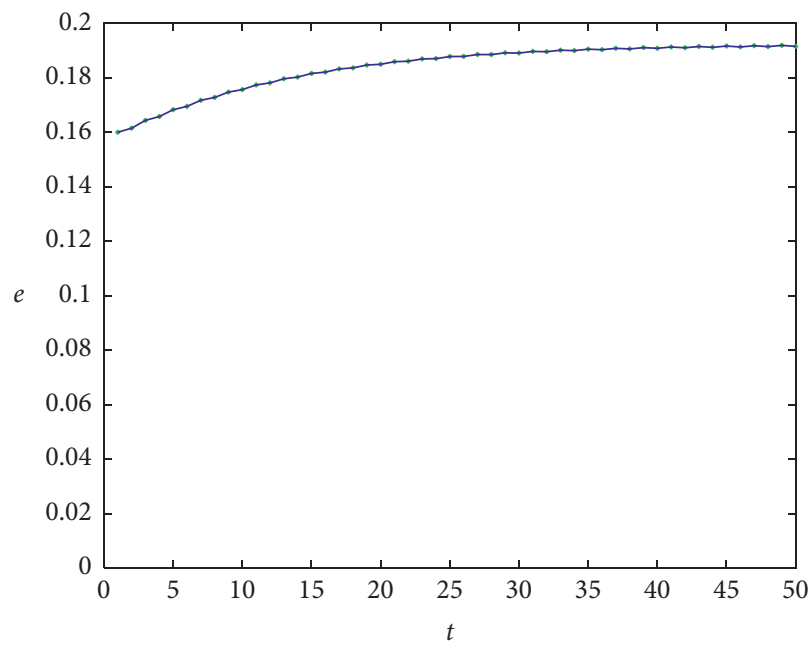

FIGURE 15: The eco-innovative effort fluctuations of the manufacturer.

$$
\left\{\begin{array}{l}
u_{1}=\delta(q(t+1-\tau)-q(t+1)), \\
u_{2}=\lambda(e(t+1-\tau)-e(t+1)),
\end{array}\right.
$$

where $\delta$ and $\lambda$ are the controlling factors and $\tau(t>\tau)$ is the length of lag time. Here, we assume $\tau$ as one period. The control system can be formulated as follows:

$$
\left\{\begin{array}{l}
q(t+1)=q(t)+\frac{\alpha_{q} q(t)(1-c+(\mu-2) q(t)+e(t) \sigma)}{1+\delta}, \\
e(t+1)=e(t)+\frac{\alpha_{e} e(t)(-2 e(t)+q(t) \sigma)}{1+\lambda} .
\end{array}\right.
$$

The Jacobi matrix of the control system is as follows:

$$
J=\left[\begin{array}{cc}
1+\frac{\alpha_{q}(1-c+2(\mu-2) q(t)+e(t) \sigma)}{1+\delta} & \frac{\alpha_{q} q(t) \sigma}{1+\delta} \\
\frac{\alpha_{e} e(t) \sigma}{1+\lambda} & 1+\frac{\alpha_{e}(-4 e(t)+q(t) \sigma)}{1+\lambda}
\end{array}\right] .
$$

The Nash equilibrium point is $E^{*}(2(c-1) /$ $\left.\left(\sigma^{2}+2 \mu-4\right), \sigma(c-1) /\left(\sigma^{2}+2 \mu-4\right)\right)$, and the above Jacobi matrix can be expressed as follows:

$$
J=\left[\begin{array}{cc}
1+\frac{2 \alpha_{q}(c-1)(\mu-2)}{(1+\delta)\left(\sigma^{2}+2 \mu-4\right)} & \frac{2 \alpha_{q} \sigma(c-1)}{(1+\delta)\left(\sigma^{2}+2 \mu-4\right)} \\
\frac{\alpha_{e} \sigma^{2}(c-1)}{(1+\lambda)\left(\sigma^{2}+2 \mu-4\right)} & 1+\frac{\alpha_{e}\left((c-1)\left(\sigma^{2}-8\right)\right)}{(1+\lambda)\left(\sigma^{2}+2 \mu-4\right)}
\end{array}\right] .
$$




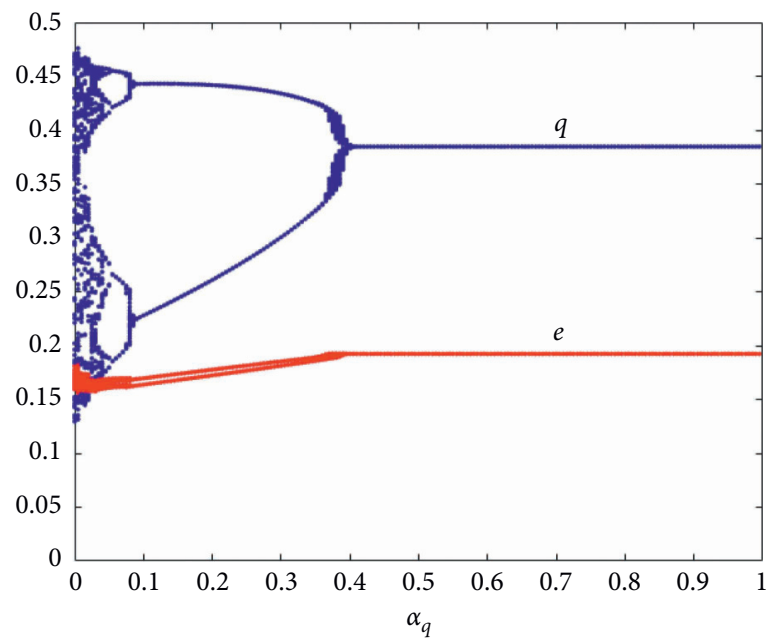

FIGURE 16: The bifurcation diagram of the controlling factors $\delta$, when $\lambda=0.6$.

From the previous numerical analysis, we can see that when $\alpha_{q}=4$ and $\alpha_{e}=0.5$, the system is chaotic. And now, the Jacobi matrix form of the control system is as follows:

$$
J=\left[\begin{array}{cc}
\frac{\delta-1.769}{1+\delta} & \frac{1.538}{1+\delta} \\
\frac{0.096}{1+\lambda} & \frac{\lambda+0.808}{1+\lambda}
\end{array}\right] .
$$

If dynamic system (25) is stable, $\delta$ and $\lambda$ need to meet the following conditions:

$$
\left\{\begin{array}{l}
2.577+0.192 \delta+2.769 \lambda>0 \\
-0.385+\delta(\lambda+0.904)-0.385 \lambda>0
\end{array}\right.
$$

As shown in Figures 14 and 15, when $\delta=0.4$ and $\lambda=0.6$, after multiple iterations, the variables $(q$ and $e$ ) tend to a fixed Nash equilibrium value ( 0.385 and 0.192$)$. It can also be clearly seen from Figure 16 that with the enhancement of the control factor $\delta$, the system changes from chaos to stability. The delayed feedback control (DFC) method is an effective method of chaos control. In this case, the manufacturer can adjust its decision by taking not only the profit of the last period as the benchmark but also the profit of the previous periods as the reference to improve the stability and effectiveness of decision-making. Through the application of the control factor, the manufacturer can guide the system to restore stability by increasing the value of the control factor. Therefore, the manufacturer can make more efficient decisions while reducing the risk of system chaos, which is beneficial to the entire supply chain.

\section{Conclusions}

This paper constructs a closed-loop supply chain composed of a manufacturer and a recycler and considers the manufacturer's CSR and recycler's fairness concern behavior into the supply chain model in turn. In addition, this paper analyzes the dynamic behavior of the dynamic decision model using bifurcation diagrams, attracting basins, and chaotic attractors and describes the effect on the average utility of the manufacturer and the recycler when the parameters change. Finally, the delayed feedback method is used to control the chaos of the system. The following conclusions can be drawn: If the manufacturer undertakes CSR within a reasonable range, the utility of the manufacturer will increase, and the utility of the recycler will be reduced. After considering fairness concerns, the manufacturer's optimal utility remains unchanged, while the recycler's utility varies according to the manufacturer's CSR proportional coefficient. Therefore, if the manufacturer considers the long-term development of their own enterprises, they should take the initiative to undertake CSR. The recycler should choose their fairness concern coefficient based on the manufacturer's CSR coefficient. As the adjustment speed increases, dynamic system (25) will enter a chaotic state through bifurcation. In the chaotic state, the average utility of both the manufacturer and the recycler will decrease. In addition, the manufacturer can select appropriate control parameters and use the delayed feedback control (DFC) method to restore dynamic system (25) from a chaotic state to a stable state.

However, the game model established in this article ignores many factors that affect the dynamic decisionmaking of the supply chain, such as consumers' purchasing intentions for eco-innovative products in the supply chain, the level of environmental awareness of consumers actively participating in products recycling, and so on. These factors will affect the actual situation. These issues will be the focus of our future research.

\section{Appendix}

\section{Proofs for Main Results}

Proof . of Proposition 1. Analyze the monotonicity of the decision variables $q^{*}, e^{*}$, and $r^{*}$ with respect to the parameters and obtain the first-order derivatives. The results are as follows: 


$$
\begin{aligned}
& \frac{\partial q^{*}}{\partial s}=\frac{2}{4-\sigma^{2}}>0, \\
& \frac{\partial q^{*}}{\partial \sigma}=\frac{4(1-c) \sigma}{\left(4-\sigma^{2}\right)^{2}}>0, \\
& \frac{\partial e^{*}}{\partial s}=\frac{\sigma}{4-\sigma^{2}}>0 \\
& \frac{\partial e^{*}}{\partial \sigma}=\frac{(1-c)\left(4+\sigma^{2}\right)}{\left(4-\sigma^{2}\right)^{2}}>0, \\
& \frac{\partial r^{*}}{\partial \theta}=\frac{(c-1) \sigma}{2 \varphi\left(\sigma^{2}-4\right)}>0, \\
& \frac{\partial r^{*}}{\partial \varphi}=\frac{\left(\sigma^{2}-4\right) k+(c-1) \theta \sigma}{2 \varphi^{2}\left(4-\sigma^{2}\right)}<0, \\
& \frac{\partial r^{*}}{\partial \sigma}=\frac{(1-c)\left(\sigma^{2}+4\right) \theta}{2 \varphi\left(\sigma^{2}-4\right)^{2}}>0 .
\end{aligned}
$$

Proof . of Proposition 2. Similar to the method of Proposition 1.

$$
\begin{aligned}
\frac{\partial \pi_{m}^{*}}{\partial \sigma} & =\frac{4(1-c) \sigma}{\left(4-\sigma^{2}\right)^{2}}>0, \\
\frac{\partial \pi_{m}^{*}}{\partial s} & =\frac{2(1-c)}{4-\sigma^{2}}>0, \\
\frac{\partial \pi_{r}^{*}}{\partial \theta} & =\frac{(c-1)^{2} \sigma(c-1) \theta \sigma+k\left(\sigma^{2}-4\right)}{\left(\sigma^{2}-4\right)^{3} \varphi}>0, \\
\frac{\partial \pi_{r}^{*}}{\partial \varphi} & =\frac{(c-1)^{2} \sigma(c-1) \theta \sigma+k\left(\sigma^{2}-4\right)}{\left(4-\sigma^{2}\right)^{3} \varphi^{2}}<0, \\
\frac{\partial \pi_{r}^{*}}{\partial s} & =\frac{3\left((c-1) \theta \sigma+k\left(\sigma^{2}-4\right)\right)^{2}}{2(c-1)^{3} \varphi}>0, \\
\frac{\partial \pi_{r}^{*}}{\partial \sigma} & =-\frac{(c-1)\left((c-1) \theta \sigma+k\left(\sigma^{2}-4\right)\right)\left(k \sigma\left(\sigma^{2}-4\right)+2 \theta\left(2+\sigma^{2}\right)(c-1)\right)}{\left(\sigma^{2}-4\right)^{4} \varphi}>0 .
\end{aligned}
$$

Proof . of Proposition 3. Analyze the sensitivity of the decision variables $q^{c^{*}}, e^{c^{*}}$, and $r^{c^{*}}$ to the CSR coefficient $\mu$ and calculate their first-order derivatives, and the results are as follows: 


$$
\begin{aligned}
& \frac{\partial q^{c^{*}}}{\partial \mu}=\frac{4(1-c)}{\left(\sigma^{2}+2 \mu-4\right)^{2}}>0, \\
& \frac{\partial e^{c^{*}}}{\partial \mu}=\frac{2(1-c) \sigma}{\left(\sigma^{2}+2 \mu-4\right)^{2}}>0, \\
& \frac{\partial r^{c^{*}}}{\partial \mu}=\frac{(1-c) \theta \sigma}{\left(\sigma^{2}+2 \mu-4\right)^{2} \varphi}>0 .
\end{aligned}
$$

In order to analyze the change trend of each decision variable and in the CSR model and the basic model, we subtract the corresponding quantity of the CSR model from the optimal decision quantity in the basic model. After the calculation, we can get

$$
\begin{aligned}
& e^{*}-e^{c^{*}}=\frac{(c-1) \sigma}{\sigma^{2}-4}-\frac{(c-1) \sigma}{2 \mu+\sigma^{2}-4}<0, \\
& q^{*}-q^{c^{*}}=\frac{2(c-1)}{\sigma^{2}-4}-\frac{2(c-1)}{2 \mu+\sigma^{2}-4}<0, \\
& e^{*}-e^{c^{*}}=\frac{(c-1) \sigma}{\sigma^{2}-4}-\frac{(c-1) \sigma}{2 \mu+\sigma^{2}-4}<0 .
\end{aligned}
$$

Therefore, $e^{c^{*}}>e^{*}, q^{c^{*}}>q^{*}$, and $r^{c^{*}}>r^{*}$.

Proof . of Proposition 4. Similar to the proof method of Proposition 1, analyze the sensitivity of the optimal profit in the CSR model to the CSR coefficient $u$ and calculate their first-order derivatives. The results are as follows:

$$
\begin{aligned}
\frac{\partial U_{m}^{c^{*}}}{\partial \mu} & =\frac{2(1-c)^{2}}{\left(-4+2 \mu+\sigma^{2}\right)^{2}}>0, \\
\frac{\partial \pi_{m}^{c^{*}}}{\partial \mu} & =\frac{8(1-c)^{2} \mu}{\left(-4+2 \mu+\sigma^{2}\right)^{3}}<0, \\
\frac{\partial \pi_{r}^{c^{*}}}{\partial \mu} & =-\frac{(-1+c)\left((-1+c) \theta \sigma+k\left(\sigma^{2}+2 \mu-4\right)\right)\left(3(c-1) \theta \sigma+k\left(\sigma^{2}+2 \mu-4\right)\right)}{\left(-4+2 \mu+\sigma^{2}\right)^{4} \varphi}<0 .
\end{aligned}
$$

Proof. of Proposition 5. Similar to the proof method of Proposition 3, in order to compare the profit and utility of manufacturer and recycler under the basic model and the
CSR model, we use their respective benefits in the basic model minus the benefits in the CSR model, and the differences between them are

$$
\begin{aligned}
& \pi_{m}^{*}-U_{m}^{c^{*}}=-\frac{2(1-c)^{2} \mu}{\left(\sigma^{2}-4\right)\left(\sigma^{2}+2 \mu-4\right)}<0, \\
& \pi_{m}^{*}-\pi_{m}^{c^{*}}=-\frac{4(1-c)^{2} \mu^{2}}{\left(\sigma^{2}-4\right)\left(\sigma^{2}+2 \mu-4\right)^{2}}>0, \\
& \pi_{r}^{*}-\pi_{r}^{c^{*}}=\frac{(c-1)\left((c-1) \theta \sigma+k\left(\sigma^{2}-4\right)\right)^{2}}{2\left(\sigma^{2}-4\right)^{3} \varphi}-\frac{(c-1)\left((c-1) \theta \sigma+k\left(\sigma^{2}+2 \mu-4\right)\right)^{2}}{2\left(\sigma^{2}+2 \mu-4\right)^{3} \varphi}>0 .
\end{aligned}
$$

Proof . of Proposition 6. In order to analyze the change trend of the fairness concerns coefficient $\eta$ on the optimal utility of the recycler, we calculate their first-order derivative as follows:

$$
\frac{\partial U_{r}^{f^{*}}}{\partial \eta}=\frac{(1-c)\left(\left((1-c) \theta \sigma-k\left(-4+2 \mu+\sigma^{2}\right)\right)^{2}+2(c-1)\left(-4+2 \mu+\sigma^{2}\right)\left(-4+4 \mu+\sigma^{2}\right) \varphi\right)}{2\left(\sigma^{2}+2 \mu-4\right) \varphi}
$$


We cannot directly judge whether the above formula is greater than zero, so we find the critical point. The expressions are as follows:

$$
\begin{aligned}
& \frac{\partial U_{r}^{*}}{\partial \eta}>0, \quad \text { when } \mu \in\left(0, \frac{4-\sigma^{2}}{4}\right), \\
& \frac{\partial U_{r}^{*}}{\partial \eta}<0, \quad \text { when } \mu \in\left(\frac{4-\sigma^{2}}{4}, \frac{4-\sigma^{2}}{2}\right] .
\end{aligned}
$$

Proof . of Proposition 7. In order to compare the optimal utility of the recycler in the three modes, we calculate the difference between them. Similar to Proposition 6, we cannot directly judge whether the result is greater than zero, so we find their critical points. The expressions are as follows:

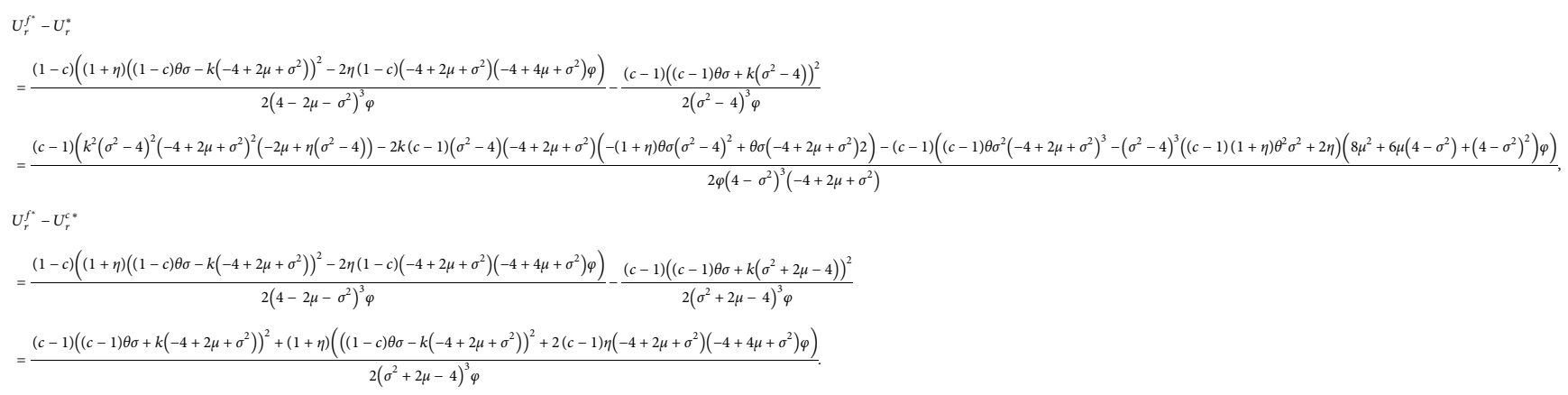

$U_{r}^{f^{*}}-U_{r}^{*}>0, U_{r}^{f^{*}}-U_{r}^{c^{*}}>0$. When $k^{2}>4(1-c) \varphi$, combine the conclusion of Proposition 5, so $U_{r}^{f^{*}}>U_{r}^{*}>U_{r}^{c^{*}}$.

When $k^{2}<4(1-c) \varphi$ and $\left(\left(k \theta \sigma(1-c)^{2}+k^{2}(c-1+\right.\right.$ $\left.\left.\left.3\left((1-c)^{2}\left(\sigma^{2}-4\right) \varphi+A\right)\right)\right) / 2\left((1-c)\left(4(1-c) \varphi-k^{2}\right)\right)\right)<\mu$, $U_{r}^{f^{*}}-U_{r}^{*}>0$ and $U_{r}^{f^{*}}-U_{r}^{c^{*}}>0$.

When $k^{2}<4(1-c) \varphi$ and $\mu<\left(\left(k \theta \sigma(1-c)^{2}+k^{2}(c-1+\right.\right.$ $\left.\left.\left.3\left((1-c) \quad 2\left(\sigma^{2}-4\right) \varphi+A\right)\right)\right) / 2\left((1-c)\left(4(1-c) \varphi-k^{2}\right)\right)\right)$, $U_{r}^{f^{*}}-U_{r}^{*}<0$ and $U_{r}^{f^{*}}-U_{r}^{c^{*}}<0$. Since the range of $\mu$ is $\mu \in\left(0,\left(\left(4-\sigma^{2}\right) / 2\right)\right)$, we know that the upper limit of the CSR coefficient $\mu$ is $\left(\left(4-\sigma^{2}\right) / 2\right)$. Combining the results we calculated above, we get the conclusion in Proposition 7.

Proof. of Proposition 8. According to the Jacobi matrix and jury criterion of dynamic system (25), the stability condition can be calculated as follows:

$$
\left\{\begin{array}{l}
4 \alpha_{e} e^{*}(t)\left(1+\alpha_{q}\left(\left(1-c+2 q^{*}(t)(\mu-2)\right)\right)-\alpha_{e} q^{*}(t) \sigma-\alpha_{q} e^{*}(t) \sigma+4 e^{*}(t)^{2} \alpha_{e} \alpha_{q} \sigma+\alpha_{q}\left(-1-c-2 q^{*}(t)(\mu-2)\right)\left(1+q^{*}(t) \alpha_{e} \sigma\right)>0\right. \\
-4 e^{*}(t) 2 \alpha_{e} \alpha_{q} \sigma+\left(2+\alpha_{q}\left(1-c+2 q^{*}(t)(\mu-2)\right)\right)\left(2+\alpha_{e} q^{*}(t) \sigma\right)+2 e^{*}(t)\left(2 \alpha_{e}\left(-2+\alpha_{q}\left(-1-c-2 q^{*}(t)(\mu-2)\right)\right) \alpha_{q} \sigma\right)>0 .
\end{array}\right.
$$

Substituting $E_{3}\left(q^{*}(t), e^{*}(t)\right)$ into the above set of inequalities, after the calculation, we can get the following:

$$
\left\{\begin{array}{l}
2(1-c)\left(\alpha_{e} \sigma-\alpha_{q}\left(\alpha_{e} \sigma(1-c)+\mu-2\right)\right)>0 \\
2 \alpha_{q}(-1+c)\left(4-2 \mu+(-1+c) \alpha_{e} \sigma\right)-4\left(\sigma^{2}+2 \mu-4+(1-c) \alpha_{e} \sigma\right)>0
\end{array}\right.
$$

Separate $\alpha_{q}$ and $\alpha_{e}$ to get the conclusion in Proposition 8 . 


\section{Data Availability}

No data were used to support this study.

\section{Conflicts of Interest}

The authors declare that they have no conflicts of interest.

\section{Acknowledgments}

This research was supported by the Research Center of Enterprise Decision Support, Key Research Institute of Humanities and Social Sciences in Universities of Hubei Province (nos. DSS20210401 and DSS20190102).

\section{References}

[1] T. Lindhqvist, Extended producer responsibility in cleaner production: policy principle to promote environmental improvements of product systems, Ph.D. dissertation, IIIEE, Lund University, Lund, Sweden, 2000.

[2] R. Lifset, "Take it back: extended producer responsibility as a form of incentive based environmental policy," Journal of Resource Management \& Technology, vol. 21, no. 4, pp. 163175, 1993.

[3] M. E. Porter and M. R. Kramer, "The link between competitive advantage and corporate social responsibility," Harvard Business Review, vol. 84, no. 12, pp. 78-92, 2006.

[4] R. Subramanian, S. Gupta, and B. Talbot, "Product design and supply chain coordination under extended producer responsibility," Production and Operations Management, vol. 18, no. 3, pp. 259-277, 2009.

[5] A. Genovese, A. A. Acquaye, A. Figueroa, and S. L. Koh, "Sustainable supply chain management and the transition towards a circular economy: evidence and some applications," Omega, vol. 66, no. 2, pp. 344-357, 2015.

[6] F. M. Tai and S. H. Chang, "Corporate social responsibility," iBusiness, vol. 6, no. 3, pp. 117-130, 2014.

[7] H. Servaes and A. Tamayo, "The impact of corporate social responsibility on firm value: the role of customer awareness," Management Science, vol. 59, no. 5, pp. 1045-1061, 2013.

[8] G. Pino, C. Amatulli, M. De Angelis, and A. M. Peluso, "The influence of corporate social responsibility on consumers' attitudes and intentions toward genetically modified foods: evidence from Italy," Journal of Cleaner Production, vol. 112, no. 1, pp. 2861-2869, 2016.

[9] S. Panda, N. M. Modak, and L. E. Cárdenas-Barrón, "Coordinating a socially responsible closed-loop supply chain with product recycling," International Journal of Production Economics, vol. 188, no. 6, pp. 11-21, 2017.

[10] S.-M. Hosseini-Motlagh, M. Nouri-Harzvili, T.-M. Choi, and S. Ebrahimi, "Reverse supply chain systems optimization with dual channel and demand disruptions: sustainability, CSR investment and pricing coordination," Information Sciences, vol. 503, no. 3, pp. 606-634, 2019.

[11] Y. Liu and T. Xiao, "Pricing and collection rate decisions and reverse channel choice in a socially responsible supply chain with green consumers," IEEE Transactions on Engineering Management, vol. 67, no. 2, pp. 483-495, 2020.

[12] G. Ferrer and J. M. Swaminathan, "Managing new and remanufactured products," Management Science, vol. 52, no. 1, pp. 15-26, 2006.

[13] A. Sharma, "Game-theoretic analysis of pricing models in a Dyadic supply chain with fairness concerns," International
Journal of Strategic Decision Sciences, vol. 10, no. 2, pp. 1-24, 2019.

[14] T. Jin, H. Ding, H. Xia, and J. Bao, "Reliability index and Asian barrier option pricing formulas of the uncertain fractional first-hitting time model with Caputo type," Chaos Solitons \& Fractals, vol. 142, no. 2, Article ID 110409, 2020.

[15] W. Deng, J. Xu, X.-Z. Gao, and H. Zhao, "An enhanced MSIQDE algorithm with novel multiple strategies for global optimization problems," IEEE Transactions on Systems, Man, and Cybernetics: Systems, vol. 58, pp. 1-10, 2020.

[16] R. C. Savaskan, S. Bhattacharya, and L. N. Van Wassenhove, "Closed-loop supply chain models with product remanufacturing," Management Science, vol. 50, no. 2, pp. 239-252, 2004.

[17] Z. Wang, B. Li, X. Zhu, B. Xin, and Y. Wang, "The impact of donation subsidy of remanufactured products on manufacturer's pricing-production decisions and performances," Journal of Cleaner Production, vol. 202, no. 20, pp. 892-903, 2018.

[18] V. Simic and B. Dimitrijevic, "Production planning for vehicle recycling factories in the EU legislative and global business environments," Resources, Conservation and Recycling, vol. 60 , pp. 78-88, 2012.

[19] Y. Li, F. Xu, and X. Zhao, "Governance mechanisms of dualchannel reverse supply chains with informal collection channel," Journal of Cleaner Production, vol. 155, no. 2, pp. 125-140, 2016.

[20] W. Zhou, Y. Zheng, and W. Huang, "Competitive advantage of qualified WEEE recyclers through EPR legislation," European Journal of Operational Research, vol. 257, no. 2, pp. 641-655, 2017.

[21] L. Wang and M. Chen, "Policies and perspective on end-oflife vehicles in China," Journal of Cleaner Production, vol. 44, pp. 168-176, 2013.

[22] X. Dong, C. Li, J. Li, W. Huang, J. Wang, and R. Liao, "Application of a system dynamics approach for assessment of the impact of regulations on cleaner production in the electroplating industry in China," Journal of Cleaner Production, vol. 20, no. 1, pp. 72-81, 2012.

[23] M. Sabaghi, C. Mascle, and P. Baptiste, "Evaluation of products at design phase for an efficient disassembly at endof-life," Journal of Cleaner Production, vol. 116, pp. 177-186, 2016.

[24] X. Chang, J. Wu, T. Li, and T.-J. Fan, “The joint tax-subsidy mechanism incorporating extended producer responsibility in a manufacturing-recycling system," Journal of Cleaner Production, vol. 210, no. 10, pp. 821-836, 2019.

[25] J. Cao, X. Zhang, L. Hu et al., "EPR regulation and reverse supply chain strategy on remanufacturing," Computers \& Industrial Engineering, vol. 125, pp. 279-297, 2018.

[26] C.-K. Chen and M. A. Ulya, "Analyses of the reward-penalty mechanism in green closed-loop supply chains with product remanufacturing," International Journal of Production Economics, vol. 210, no. 43, pp. 211-223, 2019.

[27] J. Gao, H. Han, L. Hou, and H. Wang, "Decision-making and coordination in closed-loop supply chain with social responsibility," Computer Integrated Manufacturing Systems, vol. 20, no. 6, pp. 1453-1461, 2014.

[28] N. M. Modak, N. Kazemi, and L. E. Cárdenas-Barrón, "Investigating structure of a two-echelon closed-loop supply chain using social work donation as a corporate social responsibility practice," International Journal of Production Economics, vol. 207, no. 1, pp. 19-33, 2018. 
[29] T. Shu, Q. Liu, S. Chen, S. Wang, and K. Lai, "Pricing decisions of CSR closed-loop supply chains with carbon emission constraints," Sustainability, vol. 10, no. 12, pp. 1-25, 2018.

[30] Y. Wu, H. Li, Q. Gou, and J. Gu, "Supply chain models with corporate social responsibility," International Journal of Production Research, vol. 55, no. 22, pp. 6732-6759, 2017.

[31] D. Kahneman, J. L. Knetsch, and R. Thaler, "Fairness, competition on profit seeking: entitlements in the market," American Economics Review, vol. 76, no. 4, pp. 728-741, 1986.

[32] P. Ma, K. W. Li, and Z. J. Wang, "Pricing decisions in closedloop supply chains with marketing effort and fairness concerns," International Journal of Production Research, vol. 55, no. 22, pp. 1-22, 2017.

[33] Y. Wang and J. Li, "Research on dominant models of E-CLSC based on network sale and recycle considering fairness concern," Chinese Journal of Management Science, vol. 26, no. 1, pp. 139-151, 2018.

[34] N. Wang, Z.-P. Fan, and X. Wang, "Channel coordination in logistics service supply chain considering fairness," Mathematical Problems in Engineering, vol. 2016, Article ID 9621794, 15 pages, 2016.

[35] Z. Xu and Q. Zhang, "Coordination mechanism for fresh agricultural supply chain under the retailer's fairness concerns," Journal of Systems Engineering, vol. 32, no. 4, pp. 461-473, 2017.

[36] W. Lou and J. Ma, "Complexity of sales effort and carbon emission reduction effort in a two-parallel household appliance supply chain model," Applied Mathematical Modelling, vol. 64, pp. 398-425, 2018.

[37] M. Johari, S.-M. Hosseini-Motlagh, and M. Rasti-Barzoki, "An evolutionary game theoretic model for analyzing pricing strategy and socially concerned behavior of manufacturers," Transportation Research Part E: Logistics and Transportation Review, vol. 128, no. 8, pp. 506-525, 2019.

[38] J. Ma, W. Yang, and W. Lou, "Research on bifurcation and chaos in a dynamic mixed game system with oligopolies under carbon emission constraint," International Journal of Bifurcation and Chaos, vol. 27, no. 10, Article ID 1750158, 2017.

[39] W. Lou, J. Ma, and X. Zhan, "Bullwhip entropy analysis and chaos control in the supply chain with sales game and consumer returns," Entropy, vol. 19, no. 2, p. 64, 2017.

[40] Q. Li, X. Chen, and Y. Huang, "The stability and complexity analysis of a low-carbon supply chain considering fairness concern behavior and sales service," International Journal of Environmental Research and Public Health, vol. 16, no. 15, p. 2711, 2019.

[41] J. Ma and L. Xie, "The impact of loss sensitivity on a mobile phone supply chain system stability based on the chaos theory," Communications in Nonlinear Science and Numerical Simulation, vol. 55, pp. 194-205, 2017.

[42] J. Ma, Y. Hou, W. Yang, and Y. Tian, "A time-based pricing game in a competitive vehicle market regarding the intervention of carbon emission reduction," Energy Policy, vol. 142, Article ID 111440, 2020.

[43] J. Ma, F. Zhang, and H. Jiang, "Dynamic pricing game under different channel power structures in a closed-loop supply chain," International Journal of Bifurcation and Chaos, vol. 30, no. 4, Article ID 2050052, 2020.

[44] J. Ma, S. Hou, and B. Bao, "Short-term and long-term impacts of a quick response strategy on a dual channel apparel supply chain," International Journal of Bifurcation and Chaos, vol. 29, no. 14, Article ID 1950190, 2019.
[45] F. Zhang and C. Wang, "Dynamic pricing strategy and coordination in a dual-channel supply chain considering service value," Applied Mathematical Modelling, vol. 54, no. 2, pp. 722-742, 2017.

[46] T. Li and J. Ma, "Complexity analysis of the dual-channel supply chain model with delay decision," Nonlinear Dynamics, vol. 78, no. 4, pp. 2617-2626, 2014.

[47] Q.-x. Li, Y.-h. Zhang, and Y.-m. Huang, "The complexity analysis in dual-channel supply chain based on fairness concern and different business objectives," Complexity, vol. 2018, Article ID 4752765, 13 pages, 2018.

[48] Y. Guo and J. Ma, "Research on game model and complexity of retailer collecting and selling in closed-loop supply chain," Applied Mathematical Modelling, vol. 37, no. 7, pp. 5047-5058, 2013.

[49] J. Ma and H. Wang, "Complexity analysis of dynamic noncooperative game models for closed-loop supply chain with product recovery," Applied Mathematical Modelling, vol. 38, no. 23, pp. 5562-5572, 2014.

[50] Q. Li, M. Shi, and Y. Huang, "A dynamic price game model in a low-carbon, closed-loop supply chain considering return rates and fairness concern behaviors," International Journal of Environmental Research and Public Health, vol. 16, no. 11, p. 1978, 2019.

[51] R. Sroufe, "Effects of environmental management systems on environmental management practices and operations," Production \& Operations Management, vol. 12, no. 3, pp. 416-431, 2010.

[52] G. Raz, C. T. Druehl, and V. Blass, "Design for the environment: life-cycle approach using a newsvendor model," Production and Operations Management, vol. 22, no. 4, pp. 940-957, 2013.

[53] Y. Zhou, F. Hu, and Z. Zhou, "Pricing decisions and social welfare in a supply chain with multiple competing retailers and carbon tax policy," Journal of Cleaner Production, vol. 190, pp. 752-777, 2018.

[54] B. Du, Q. Liu, and G. Li, “Coordinating leader-follower supply chain with sustainable green technology innovation on their fairness concerns," International Journal of Environmental Research and Public Health, vol. 14, no. 11, pp. 1357-1379, 2017.

[55] Y.-h. Zhang, W. Zhou, T. Chu, Y.-d. Chu, and J.-n. Yu, "Complex dynamics analysis for a two-stage Cournot duopoly game of semi-collusion in production," Nonlinear Dynamics, vol. 91, no. 2, pp. 819-835, 2018.

[56] J. Zhou, W. Zhou, T. Chu, Y.-x. Chang, and M.-j. Huang, "Bifurcation, intermittent chaos and multi-stability in a twostage Cournot game with R\&D spillover and product differentiation," Applied Mathematics and Computation, vol. 341, pp. 358-378, 2019.

[57] R. L. Devaney and J. P. Eckmann, "An introduction to chaotic dynamical systems,” Physics Today, vol. 40, no. 7, p. 72, 1987.

[58] G. I. Bischi and A. Naimzada, "Global analysis of a dynamic duopoly game with bounded rationality," Advances in Dynamic Games and Applications, vol. 5, pp. 361-385, 2000.

[59] A. Agliari, G. I. Bischi, R. Dieci, and L. Gardini, "Global bifurcations of closed invariant curves in two-dimensional maps: a computer assisted study," International Journal of Bifurcation and Chaos, vol. 15, no. 4, pp. 1285-1328, 2005.

[60] J. Andaluz and G. Jarne, "Stability of vertically differentiated Cournot and Bertrand-type models when firms are boundedly rational," Annals of Operations Research, vol. 238, no. 2, pp. 1-25, 2016. 
[61] J.-g. Du, T. Huang, and Z. Sheng, "Analysis of decisionmaking in economic chaos control," Nonlinear Analysis: Real World Applications, vol. 10, no. 4, pp. 2493-2501, 2009.

[62] J. A. Hoyst and K. Urbanowicz, "Chaos control in economical model by time-delayed feedback method," Physica A: Statistical Mechanics and Its Applications, vol. 287, no. 3, pp. $587-598,2000$.

[63] A. Matsumoto, "Controlling the Cournot-Nash chaos," Journal of Optimization Theory and Applications, vol. 128, no. 2, pp. 379-392, 2006

[64] T. Li, D. Yan, and X. Ma, "Stability analysis and chaos control of recycling price game model for manufacturers and retailers," Complexity, vol. 2019, Article ID 3157407, 13 pages, 2019.

[65] K. Pyragas, "Continuous control of chaos by self-controlling feedback," Physics Letters A, vol. 170, no. 6, pp. 421-428, 1992.

[66] X. Ma, C. Bao, and L. Su, "Analysis of complex dynamics in different bargaining systems," Complexity, vol. 2020, Article ID 8406749, 16 pages, 2020. 